\title{
A Systematic Analysis of Seismic Moment Tensor at The Geysers Geothermal Field, California
}

\author{
by O. Sierra Boyd, Douglas S. Dreger, Voon Hui Lai," and Roland Gritto
}

\begin{abstract}
The Geysers geothermal field is one of the most seismically active regions in northern California. Most of the events occur at shallow depths and are related to stress and hydrological perturbations due to energy production operations. To better understand the relationships between seismicity and operations, better source mechanism information is needed. Seismic moment tensors offer insight into the nature of equivalent forces causing the seismicity. Fifty-three $M>3$ events located at The Geysers geothermal field were selected from the University of California Berkeley Moment Tensor Catalog for analysis of seismic moment tensor solutions and associated uncertainties. Deviatoric and full moment tensor solutions were computed, and statistical tests were employed to assess solution stability, resolution, and significance. In this study, we examine several source models including double-couple (DC), pure isotropic (ISO; volumetric change), and volume-compensated linear vector dipole (CLVD) sources, as well as compound sources such as DC + CLVD, DC + ISO, and shear-tensile sources. In general, we find from a systematic approach toward characterizing uncertainties in moment tensor solutions that The Geysers earthquakes, as a population, deviate significantly from northern California seismicity in terms of apparent volumetric source terms and complexity.
\end{abstract}

Online Material: Figures showing map of The Geysers with locations and deviatoric moment tensor solutions, distributions of isotropic parameter, $K$, for the 19922012 Berkeley Seismological Laboratory (BSL) catalog and studied events at The Geysers, and constrained moment tensor analysis of selected events. Catalogs of deviatoric and full moment tensor solutions.

\section{Introduction}

Geothermal energy has been produced at The Geysers geothermal field in northern California since the early 1960s. Seismic monitoring by Lange and Westphal (1969) showed the existence of earthquakes in The Geysers area, predominantly along the Sulfur Creek fault zone and within the area of hydrothermal activity. With the initiation of fluid injection in 1969 (Enedy et al., 1991), further seismic monitoring by Hamilton and Muffler (1972) characterized the increasing microseismicity. Marks et al. (1978) determined that seismicity was induced by steam withdrawal and or reinjection of condensate.

It has been demonstrated that increased steam production and fluid injection correlates positively with changes in earthquake activity (Majer and McEvilly, 1979; Eberhart-Phillips and Oppenheimer, 1984; Oppenheimer, 1986; Stark, 1990; Enedy et al., 1991; Greensfelder, 1993; Kirkpatrick et al., 1999;

*Now at California Institute of Technology, Seismological Laboratory, 1200 E. California Boulevard, MS 252-21, Pasadena, California 911252100.
Ross et al., 1999; Smith et al., 2000; Majer and Peterson, 2005), resulting in thousands of tiny earthquakes each year with events ranging in magnitude up to 4.5 (Majer et al., 2007). Although the locations of earthquakes and the timing and rates of their occurrence correlate with production and injection activities, little is known about the physical mechanisms. Are they predominantly double couple (DC) in nature, occurring on existing fractures and fault networks responding to stress perturbations resulting from these activities, or do the events have sources that deviate from a pure DC, which might be indicative of fluid involvement in the source process, such as tensile cracks or shear-tensile mechanisms? In the past, a small number of Geysers events with $M>4$ have occurred with the microseismicity. More recently, however, there has been an increase in the number and rates of $M>4$ events located within the microseismic cloud at The Geysers. Understanding the role of induced seismicity and the physical mechanisms of these larger-magnitude events associated with geothermal energy operations is needed to evaluate seismic hazard associated with reservoir production. 
Seismic moment tensor analysis can be used to determine the source mechanism and stress environment for larger events. Moment tensor analysis at The Geysers has evolved over the years, beginning with a frequency domain approach developed by O'Connell and Johnson (1988). Subsequent investigations by Julian et al. (1993) and Kirkpatrick et al. (1996) found evidence of nonshear source mechanisms at The Geysers. Ross et al. (1999) used a method of inverting $P$-wave first motions and $P / S$ amplitude ratios to study small events in The Geysers and found evidence for non-DC earthquakes, some of which were comprised of large compensated linear vector dipole (CLVD) solutions with cases of both volumetric expansion and compaction. Recent investigations (Guilhem et al., 2014; Johnson, 2014a,b) show a range of source mechanisms, including both shear and tensile processes.

In other geothermal and volcanic environments, non-DC moment tensor solutions have been found. For example, Nettles and Ekstrom (1998) reported solutions for seismic events associated with the Bardarbunga volcanic eruption in Iceland that are characterized as vertically oriented, CLVD with major vector dipole in tension, which they interpret as evidence of ring faulting associated with caldera collapse. Tkalcic et al. (2009) and Fichtner and Tkalcic (2010) studied these events and found that there is no volumetric component to the moment tensor and demonstrated that the observed solution could also arise from spatially offset volume-increase sources (dikes and sills) and volume-decrease sources (supplying magma chamber). In 1997, a sequence of moderate earthquakes was observed during a heightened period of seismic activity, deformation, and degassing at the Long Valley Caldera of eastern California. Over 24,000 recorded events occurred between January 1997 and February 1998 (Barton et al., 1999). Four of these had source solutions with statistically significant isotropic components (e.g., Dreger et al., 2000; Minson and Dreger, 2008). A comprehensive study of Long Valley seismicity confirmed the four unusual solutions and found one more event that had a resolvable isotropic component (Templeton and Dreger, 2006); however, most of the studied events were found to not deviate significantly from a pure DC solution. Minson et al. (2007) studied regional distance broadband waveforms of the June 2000 Miyakejima, Japan, earthquake swarm and found that many of these events had large isotropic solutions that could be indicative of tensile processes from fluids exsolving from magma along a 20-km-long propagating dike following caldera collapse at Miyakejima. Shimizu et al. (1987) proposed a tensile crack coupled with a shear crack as the source mechanism of short-period earthquakes associated with the 1983 eruption of Miyakejima.

There has also been focus on determining moment tensor solutions for earthquakes induced by hydraulic fracture stimulation (Baig and Urbancic, 2010) and borehole injection in the reservoir at Soultz-sous-Forets, France, hot-dry-rock (HDR) geothermal site. Cuenot et al. (2006) analyzed data from the 2003 hydraulic stimulation experiment and observed a higher proportion of the non-DC component for earthquakes near the injection well. On the other hand, Horalek et al. (2010) studied 45 of the largest $M$ 1.4-2.9 earthquakes from a 2003 borehole injection experiment and found that DC mechanisms dominated the sequence. Godano et al. (2011) studied four microearthquakes induced in the Soultz-sous-Forets HDR reservoir and obtained moment tensor solutions having high uncertainty associated with low isotropic and CLVD components. Deichmann and Giardini (2009) found that seismicity induced by the enhanced geothermal system of Basel, Switzerland, generally have focal mechanisms that indicate shear failure on preexisting faults, with some focal mechanisms showing signs of non-DC components with volume change.

In all studies of this type, the challenge lies in ascertaining the resolution of the various source components, their significance, and uncertainty. A systematic procedure for the evaluation of aleatoric and epistemic solution uncertainty for nuclear monitoring has been developed by Ford et al. (2008, 2009, 2010, 2012). These studies introduced techniques for the assessment of solution stability with the objective of critically examining non-DC components of derived moment tensor solutions. The effects of velocity model, station configuration, random errors, and noise levels were all utilized to inform a level of confidence on possible non-DC moment tensor solutions for the purpose of identifying nuclear explosions from earthquake signals. This approach is extensible to other classes of seismic events, such as underground cavity collapses (Ford et al., 2008), alpine glacier icequakes (Walter et al., 2009, 2010), and seismicity in environments with high fluid and/or gas pressure (Nayak and Dreger, 2014).

Recent studies at The Geysers include Johnson (2014a,b), who investigated time-dependent moment tensors of $M<3$ earthquakes from 2011 to 2012, and Guilhem et al. (2014), who obtained full moment tensor solutions of $M \sim 3$ earthquakes from 2009 to 2011 using waveform modeling and first-motion polarity. Both studies investigated earthquakes in the northern region of The Geysers using short-period seismic data from a local network and show a range of source mechanisms, including both shear and tensile processes. In the investigation presented here, broadband seismic data from regional networks are used to study moment tensors of $M>3$ earthquakes throughout the geothermal field. We apply techniques described in the next section to develop a catalog of deviatoric and full moment tensor solutions and an assessment of the resolution of non-DC components of 53 earthquakes that occurred at The Geysers from 1992 to 2014.

\section{Methodology}

We invert three-component, complete waveform data from broadband stations of the Berkeley Digital Seismic Network, Northern California Seismic System (NCSS), and the Transportable Array deployment (2005-2007) of the National Science Foundation EarthScope experiment (see Data and Resources) for deviatoric and full, six-element moment tensors, using the method outlined in Minson and Dreger 
(a)

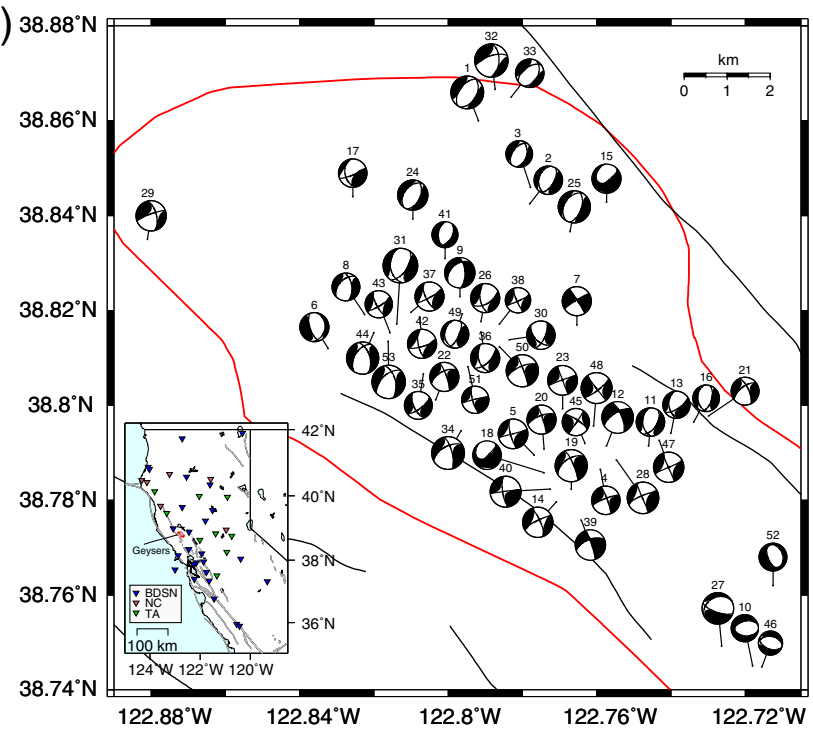

(b)

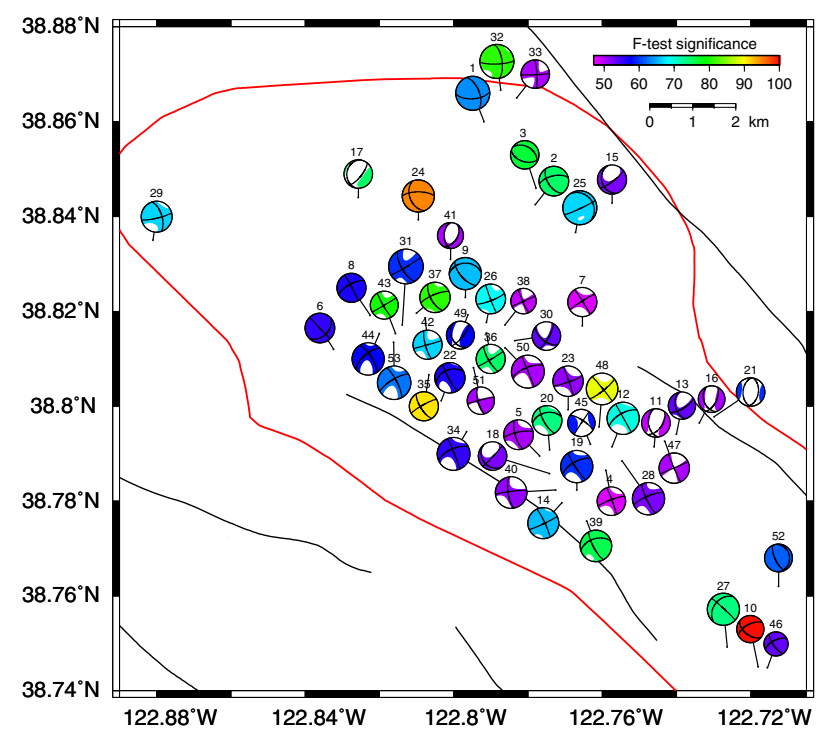

Figure 1. (a) Deviatoric moment tensor solutions of numbered events listed in Tables 1 and 2. The dashed line shows the extent of the geothermal steam field (C. Hartline, Calpine, personal comm., 2012), and solid lines indicate the surface traces of known faults. The inset shows the locations of broadband stations used in the analysis. (b) Full moment tensor (FMT) solutions, shaded by the statistical significance of the isotropic component as determined by the $F$-test, of numbered events listed in Tables 1 and 2 . The color version of this figure is available only in the electronic edition.

(2008). The broadband velocity data from stations located at distances between 30 and $400 \mathrm{~km}$ are instrument corrected with reported pole-zero response functions, integrated to displacement, and filtered with an acausal, four-pole, Butterworth band-pass filter with a $0.02-0.05$ or $0.02-0.10 \mathrm{~Hz}$ passband, depending on station distance and signal-to-noise levels in the respective passbands. It was not possible to use one set of stations for all events because of changes in the seismic networks and changes in signal-to-noise levels. In each case, we maximized the number of stations depending on signal-to-noise levels. The station locations are shown in the inset of Figure 1a.

Green's functions for the inversion were computed for the GIL7 and SOCAL 1D velocity models, which are derived from broadband waveform modeling and routinely used by the Berkeley Seismological Laboratory (BSL) to monitor California seismicity (e.g., Pasyanos et al., 1996). The Green's functions, including near-, intermediate-, and farfield terms for body and surfaces waves, were computed with FKRPROG written by Chandan Saikia, which is based on the method of Wang and Herrmann (1980).

The processed seismic waveform data are inverted for deviatoric and full moment tensor solutions following the methods outlined in Minson and Dreger (2008) and Ford et al. $(2008,2009,2010)$. In addition to finding best-fitting solutions, we apply the $F$-test to test the significance of models with higher degrees of freedom, jackknife tests to assess the stability of solutions due to station configuration, a residuals bootstrap to characterize random aleatoric variability in the solutions, and finally the network sensitivity solution (NSS; Ford et al., 2010) to map the full moment tensor solution goodness of fit in the complete source-type space (Hudson et al., 1989). Further discussion of these statistical tests is provided in later sections. All of these tests require significant computational effort; therefore, a staged approach is taken in which no additional analysis is performed if a solution is largely DC. If a solution has large non-DC components such as a CLVD (Knopoff and Randall, 1970) and/or a volumetric term, an $F$-test is first performed to assess significance of the more complex model. If the $F$-test indicates a significant improvement in fit with the non-DC terms, then the jackknife, bootstrap, and NSS analyses are performed to assess the stability of the solution and the confidence in the recovery of the non-DC components.

In the course of our study, we found that the depth sensitivity of data filtered between 0.02 and $0.05 \mathrm{~Hz}$ is fairly limited. We therefore restrain our analysis to event depths determined from the NCSS catalog, which utilizes data recorded by local Lawrence Berkeley National Laboratory (LBNL) and U.S. Geological Survey (USGS) stations. In the future, with better-calibrated velocity models and/or seismic data recorded with local stations, we may be able to improve on moment-tensor-based source depth determination. However, for now we assume that the depths reported in the cata$\log$ are well determined and focus on the recovery of the seismic moment tensor source parameters.

\section{Results}

\section{Catalog Statistics}

In Figure 1a, deviatoric moment tensors solutions are shown for the studied events. These solutions show a predominantly east-southeast tensile axis varying from relatively rare strike-slip events to more common normal-faulting events. Large CLVD solutions can accompany both of these DC types. 
One important exception is in the southeast Geysers, where the tensile axis is oriented north-south. For comparison, the full moment tensor solutions are shown in Figure 1b. Here, the moment tensors are shaded by the statistical significance of the isotropic component recovered from the full moment tensor inversion, as determined by the $F$-test. There are several solutions in which the statistical significance is relatively high. It is interesting to note that the DC component of these solutions is more consistent with the strike-slip mechanisms shown in Figure 1a. Most of the deviatoric and full moment tensor solutions show an orientation of east-southeast for the tensile axes that is consistent with recent moment tensor investigations of Johnson (2014a,b) and Guilhem et al. (2014) and recent stress studies using focal mechanisms by MartinezGarzon et al. (2013) and Boyle and Zoback (2014). However, for the few earthquakes in the southeast Geysers, the orientation of the tensile axes is rotated north-northeast and is consistent with Kirkpatrick et al. (1996), who investigated earthquakes in the southeast Geysers. They found the orientation of principal axes of moment tensors with positive volumetric components to be consistent with a normal-faulting mechanism and rotated from the regional tectonic stress.

One event (event 10) has a large isotropic component with a very high measure of statistical significance. It occurred on 12 October 1996 in the southern end of the field. The deviatoric solution for this event and others nearby show an unusual east-west-striking normal solution. The deviatoric and full moment tensor solutions for all studied events are given in Tables 1 and 2, respectively. Full moment tensor solutions having greater confidence as determined by the $F$-test and other statistical and sensitivity analyses described below are indicated by asterisks. These events are more fully investigated in a later section, and (E) some results are available in the electronic supplement to this article.

Statistical Comparison of Northern California and The Geysers Full Moment Tensor Catalogs

Because the decomposition of the seismic moment tensor is nonunique, it is useful to consider full moment tensor solutions in the Hudson et al. (1989) source-type space. This representation plots the ratio of the largest and smallest deviatoric eigenvalues $(T)$ on the $x$ axis, and the ratio of the isotropic moment and total moment ( $K$; Bowers and Hudson, 1999 ) on the $y$ axis. $T$ and $K$ are defined below. The eigenvalues of the full moment tensor are $m_{1}, m_{2}$, and $m_{3}$.

$$
T=\frac{2 m_{1}^{\mathrm{dev}}}{\left|m_{3}^{\mathrm{dev}}\right|}, \quad \text { in which }\left|m_{3}^{\mathrm{dev}}\right| \geq\left|m_{2}^{\mathrm{dev}}\right| \geq\left|m_{1}^{\mathrm{dev}}\right|
$$

and

$$
\begin{aligned}
K & =\frac{M_{0}^{\text {iso }}}{\left|M_{0}^{\text {iso }}\right|+\left|m_{3}^{\text {dev }}\right|}, \\
\text { in which } M_{0}^{\text {iso }} & =\left(m_{3}+m_{2}+m_{1}\right) / 3 .
\end{aligned}
$$

$T$ and $K$ range from -1 to 1 . Hudson et al. (1989) introduced a mapping that results in a uniform distribution of $T$ and $K$ presented in a Cartesian coordinate system with two parameters $u$ and $v$, which can range from -1 to 1 , that represent the deviatoric and volumetric components of the moment tensor in the same manner as $T$ and $K$.

Full moment tensor solutions from the 1992-2012 BSL catalog, consisting of 828 events and excluding The Geysers events in this study, were computed from the Northern California Earthquake Data Center database. Figure 2a shows the source-type plot for these 828 events distributed throughout northern California and The Geysers, denoted by plusses and circles, respectively.

Dreger et al. (2000) and Templeton and Dreger (2006) use the $F$-test to assess the statistical significance of the higher-degree-of-freedom full moment tensor solution compared with the lower-degree-of-freedom deviatoric solution. This test is based on the ratio of the model fit variance for the two cases normalized by the number of uncorrelated data. As in Dreger et al. (2000), we use the temporal width of the applied Butterworth filters to assess the degree of correlation of samples in the data time histories. For example, we are commonly inverting $120 \mathrm{~s}$ of 1 sample/s data for a threecomponent station, resulting in 360 independent data points. For a $20 \mathrm{~s}$ Butterworth filter, we consider only 18 independent data points in computing the $F$-test significance. With this conservative approach, Figure 2 a shows that the vast majority of northern California events have $F$-test significance less than $50 \%$ (549 out of 828 events), and only five events have significance above $90 \%$. Of these, three occurred in Long Valley between 1995 and 1998 (Dreger et al., 2000; Templeton and Dreger, 2006), one occurred $102 \mathrm{~km}$ north of The Geysers, and one occurred offshore of Arcata, California. These latter two may be due to poor station coverage. When Geysers solutions are evaluated with this test, 6 events are above $80 \%, 3$ events are above $90 \%$, and only 1 event meets the very stringent criteria of better than $99 \%$ significance. Thus, The Geysers is unusual with a high number of possibly statistically significant volumetric moment tensor solutions. It is interesting that, for all of the Geysers events with relatively high statistical significance, their solutions have components of volume increase, in contrast to Ross et al. (1999), who showed both volume-increase and volume-decrease source mechanisms from their first-motion and body-wave amplitude ratio analysis.

Fitting a multivariate normal distribution to the northern California data reveals that the mean in $T, K$ space is -0.0132 and 0.0182 , essentially indicating that the distribution is centered on DC mechanisms for these events. On the other hand, the 53 Geysers events (Fig. 2b) are shifted substantially away from the DC origin, and the mean of the distribution in $T$ and $K$ space is -0.0177 and 0.3331 . The Geysers events stand out as a population with the largest $K$ values in the volume increase region (upper half) of Figure $2 \mathrm{a}$. The $K$ parameter of both the BSL and Geysers catalogs is normally distributed with unequal sample variance of 0.04 and 0.03 , 


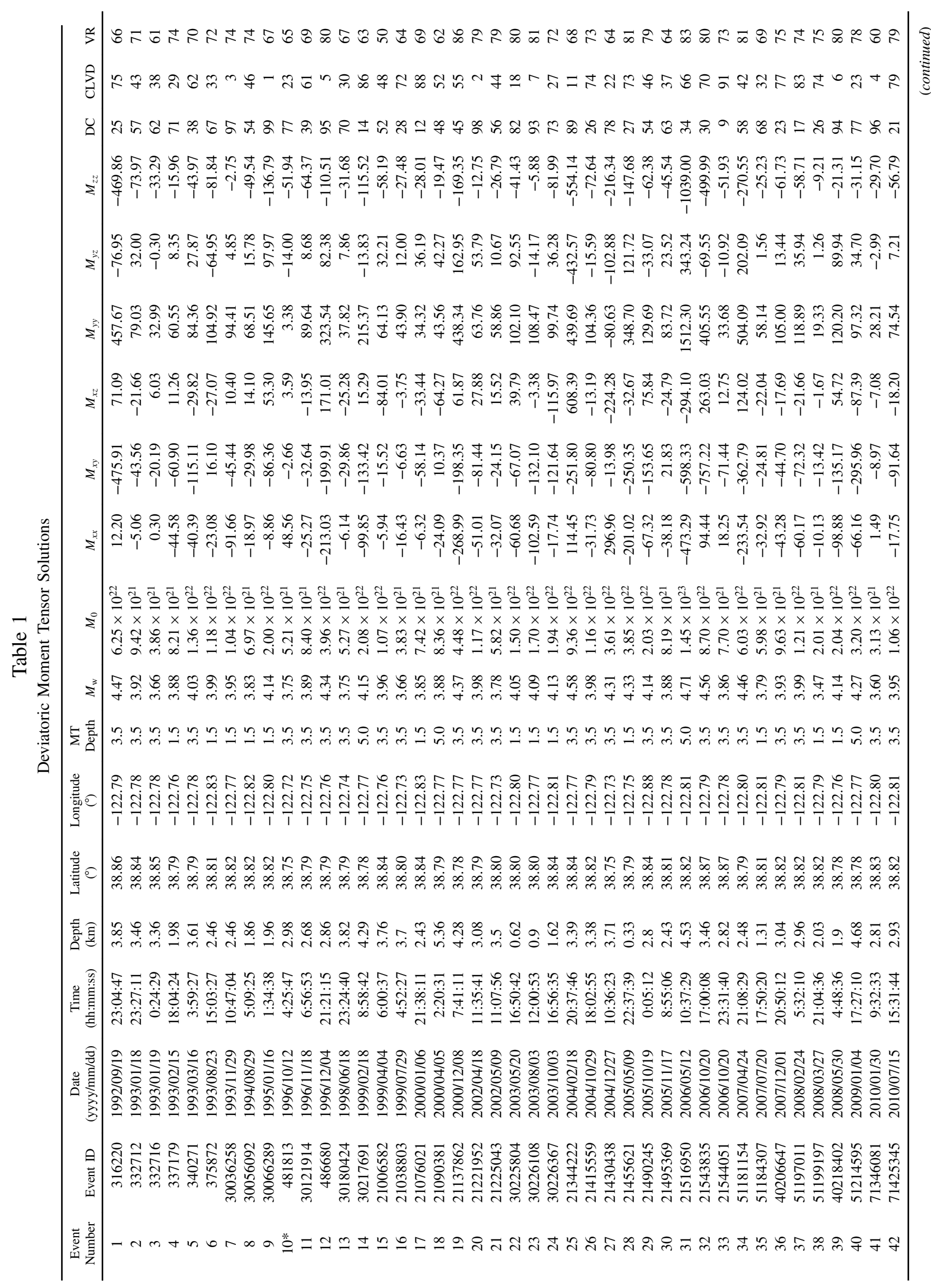




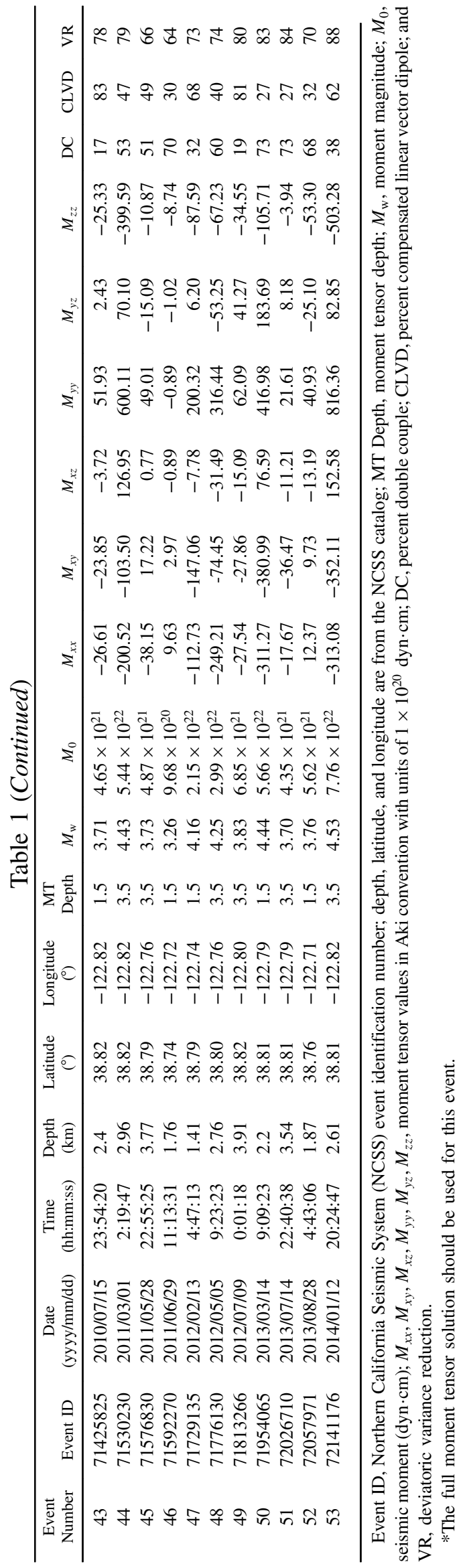

respectively (see (E) Fig. S2). The separation of the means in the two populations is 0.32 , a $99.9 \%$ statistically significant shift that corresponds to greater than $2 \sigma$ of the northern California event distribution as computed by the two-sample $t$-test of unequal sample sizes (Bock et al., 2010).

\section{Case Study of Selected End-Member Events}

Example of a Dominant DC Event. First, we consider event $41, M_{\mathrm{w}} 3.6$ on 30 January 2010 , with a dominant DC solution. Figure 3 shows the waveform fits, $P$-wave radiation pattern, and the NSS (Ford et al., 2010) of the full moment tensor. For six three-component stations, the deviatoric solution fits at $60.4 \%$, measured by the variance reduction (VR) shown as equation (3), in which $d$ and $s$ are data and synthetic seismograms, respectively:

$$
\mathrm{VR}=\left(1-\frac{\sum(d-s)^{2}}{\sum d^{2}}\right) \times 100 .
$$

This event features an $80 \%$ DC component with the full moment tensor solution showing a low level of statistical significance of only $50.84 \%$. The NSS maps the maximum fit surface by considering as many as 200 million moment tensor solutions uniformly distributed in source-type space and has been shown to be a useful tool in event source-type discrimination (e.g., Ford et al., 2012; Chiang et al., 2014). For event 41 , we find that the best-fit region is centered near the DC solution. The $98 \%$ fit contour indicates uncertainty in the solution, showing that good levels of fit can also be obtained with mixtures of approximately $20 \%$ volume increase and $\pm 40 \%$ CLVD. As mentioned before, the improved fit afforded by the extra degree of freedom of the volumetric component is not statistically significant compared to the deviatoric solution. The restrained deviatoric moment tensor inversion results in a DC component of $96 \%$ of the total seismic moment, and thus the interpretation for this event is that it has a DC mechanism.

Example of an Anomalous Large Isotropic Component Moment Tensor. Next, we compare the result for event 10, $M_{\mathrm{w}} 3.75$ on 12 October 1996 in the southeast region of the geothermal field, which has a large non-DC moment tensor solution (Fig. 1b). The $F$-test for a solution utilizing 10 threecomponent stations results in a statistical significance of $99 \%$, indicating this event is anomalous compared to both the northern California catalog and the 53 Geysers events considered in this study.

Recorded data and synthetic waveforms for event 10 are shown in Figure $4 \mathrm{a}$ and $4 \mathrm{~b}$ for the deviatoric and full moment tensor solutions, respectively. Using waveforms from 10 stations, the deviatoric solution yields a VR of $65.3 \%$, as measured by equation (3). However, the full moment tensor solution results in a substantially better VR of $77.6 \%$. Given the number of stations, components, the corresponding data samples, and consideration of the degree to which individual 


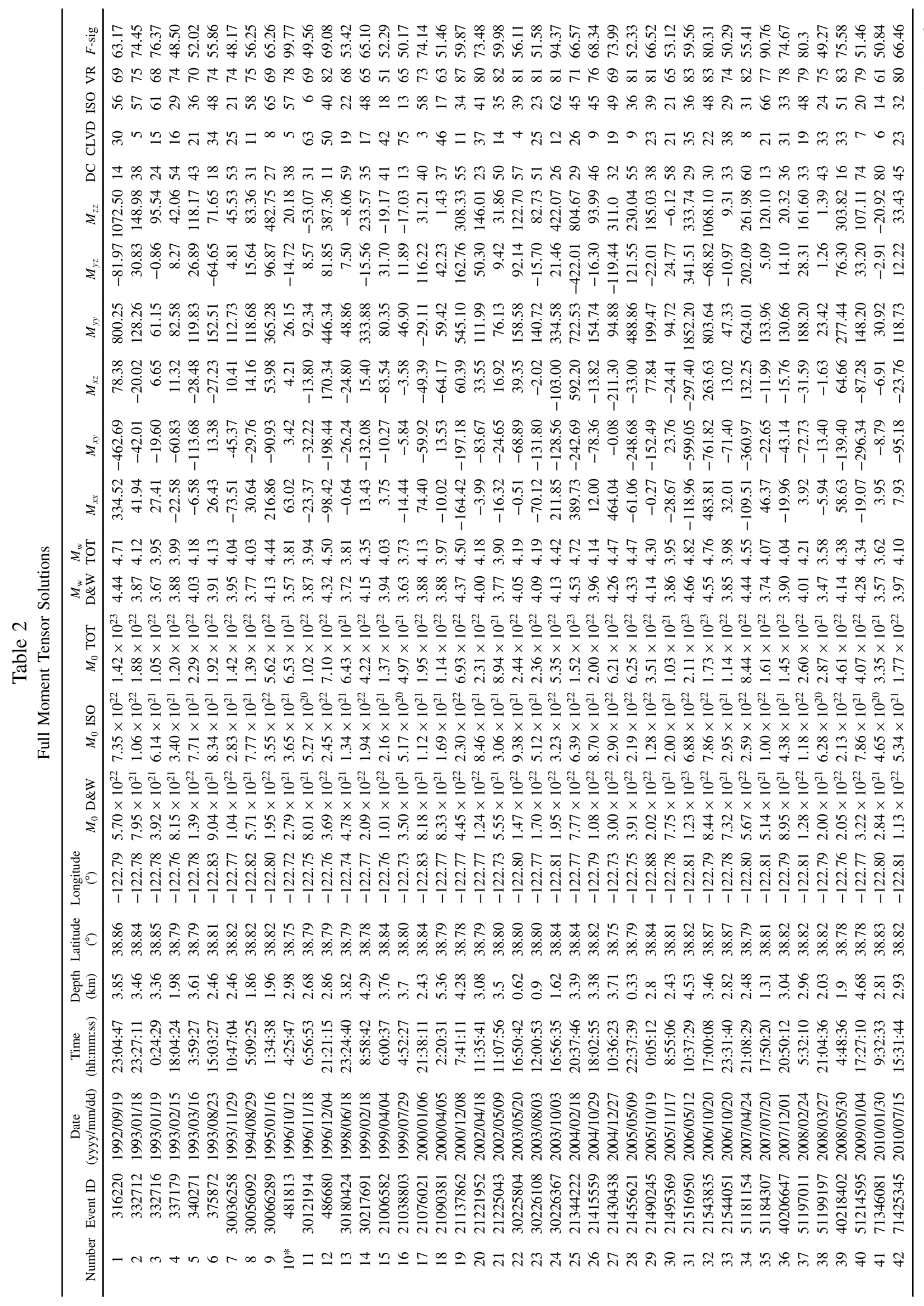




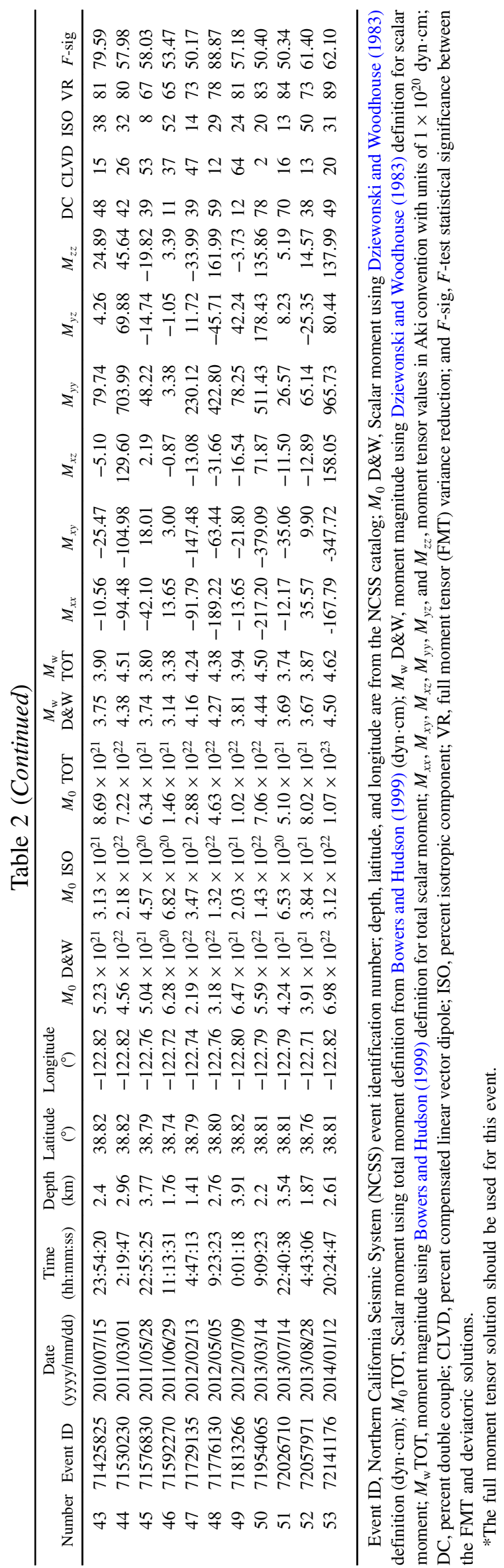

samples are correlated through the applied low-pass filter (e.g., as defined in Dreger et al., 2000), as described above, the full moment tensor solution represents an improvement in fit above the $99 \%$ level and has a larger 57\% volumeincrease component.

To examine the stability of the full moment tensor solution, we apply a jackknife test on station subsets. The jackknife test is performed by inverting all combinations of $9,8,7$, and 6 stations from the full 10-station set and plotting the $T$ and $K$ parameters on a source-type plot (Fig. 5). The best 10-station solution is shown with a star, and the 9-, 8-, 7-, and 6-station solutions are indicated with circles. The majority of the groups that have a smaller isotropic component are composed of six stations and have one station in common, HOPS. These tests show that no single station or particular azimuth is biasing results toward a non-DC solution and that the solution is very stable.

Random errors in the solution are found by bootstrapping residuals from which the residuals between observed and synthetic waveforms from the best-fitting solution are then randomly applied to the data. The data are then reinverted. We test 10,000 realizations. Although random noise could be used, actual signal-to-noise levels are low, and thus the estimated uncertainty would be quite low. Application of residuals assigns errors at a level that the applied model (velocity model Green's functions and moment tensor solution) fails to fit the data. Using the residuals instead of an a priori estimate of noise is both more conservative and meaningful. Figure 6 shows that the aleatoric uncertainty in the non-DC solution is very small.

It is interesting to examine the decomposition of the full moment tensor solution for the different tested source depths. Figure 7a shows the source depth is shallow with the bestfitting depth of $3.5 \mathrm{~km}$, which is consistent with the catalog depth of 2.98 (Table 1). Figure $7 \mathrm{~b}$ shows all of the solutions have relatively small DC components (generally less than $45 \%$ ). As the source depth gets deeper, the solution becomes dominantly isotropic, and there are no solutions that result in a large DC or a small isotropic solution over the range of depths. The $F$-test level of significance at depth $1.5 \mathrm{~km}$ is $50.6 \%$ and increases to over $99 \%$ at greater depths. It is important to note that, in general, The Geysers events tend to be shallow (less than $5 \mathrm{~km}$ ), as shown in (E) Figure S1.

In Figure 8, we show the NSS maximum fit surface considering 200 million uniformly distributed moment tensors, testing the solutions against the 10 three-component waveforms shown in Figure 4. The upper fields are showing 90\%, $95 \%$, and $98 \%$ of the best-fit solution. The DCs and deviatoric solutions fit, at best, only $80 \%$ of the best-fit solution. A striking observation is the considerably different goodness-of-fit surface compared to the previous DC case, which demonstrates the anomalous nature of the seismic radiation in event $10 \mathrm{com}-$ pared to event 41. A similar difference in NSS was found for the 2009 Democratic People's Republic of Korea nuclear explosion and a nearby Chinese earthquake (Ford et al. 2010) 

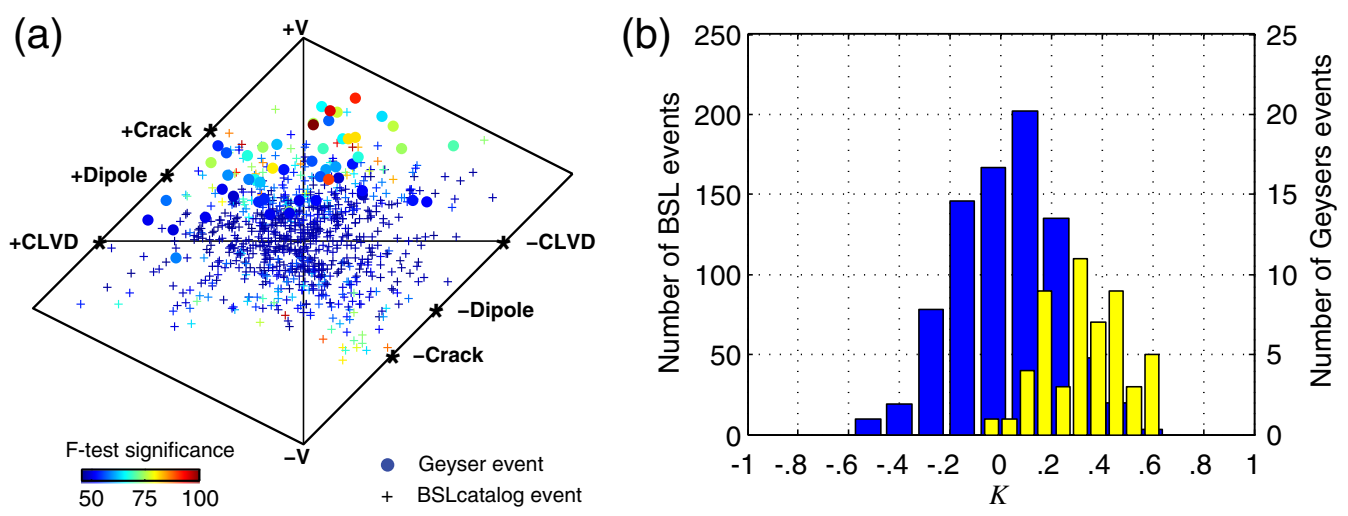

Figure 2. (a) Source-type plot of 828 events from the Berkeley Seismological Laboratory (BSL) catalog (plusses) and 53 events from The Geysers (circles), shaded by statistical significance as determined by the $F$-test. (b) Histogram of the isotropic parameter $K$ for the BSL catalog (background distribution), with the number of BSL events along the left axis and the number of events at The Geysers (foreground) along the right axis. The color version of this figure is available only in the electronic edition.

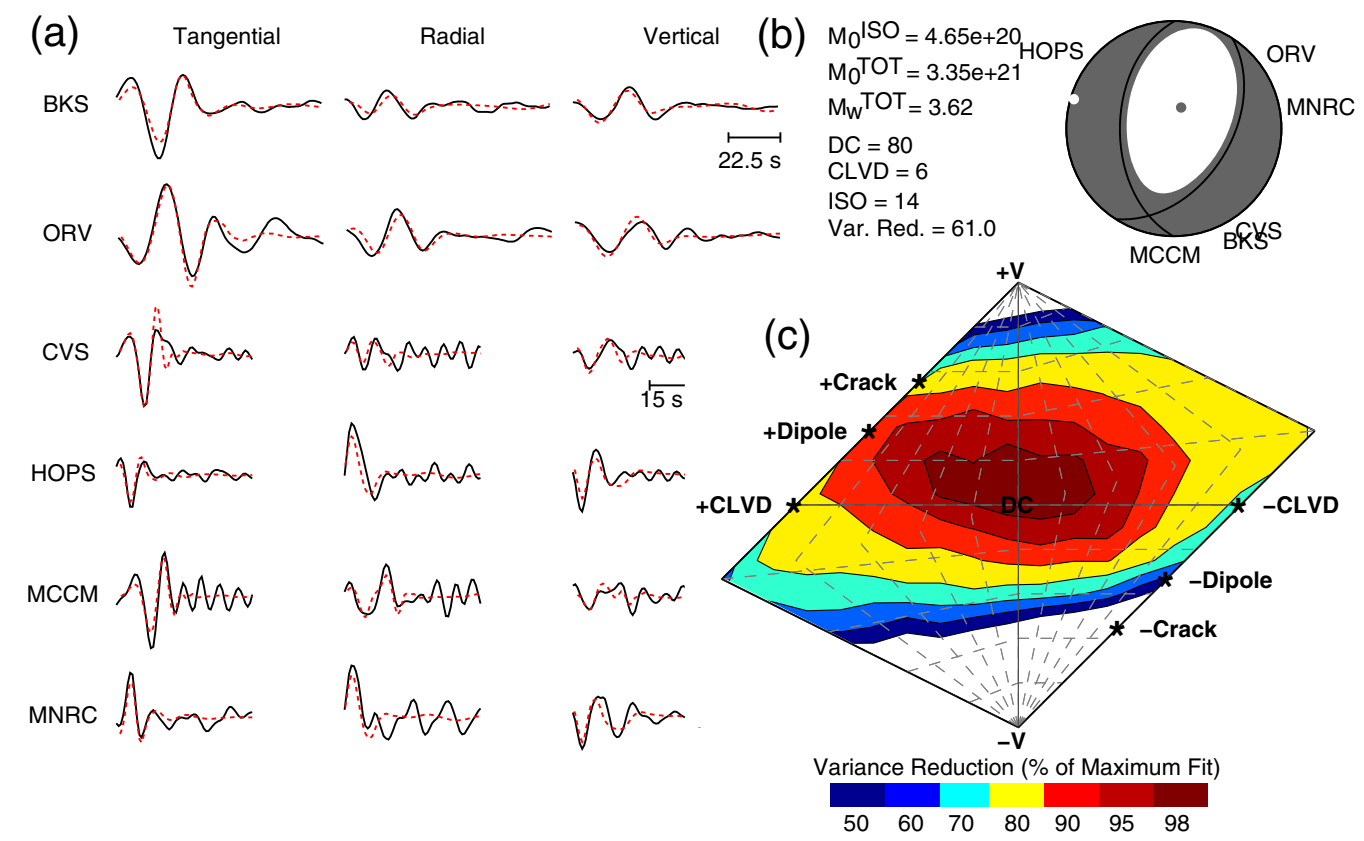

Figure 3. Event 41, 30 January $2010 M_{\mathrm{w}}$ 3.6: (a) observed (solid) and synthetic (dotted) waveforms from the FMT solution with $80 \%$ double couple (DC), $6 \%$ compensated linear vector dipole (CLVD), and 14\% isotropic (ISO) components. (b) The FMT inversion yields a mostly normal focal mechanism. (c) The network sensitivity solution (NSS) plot shows a maximum fit surface in source-type space. The fit is scaled to maximum fit found from 200 million uniformly distributed moment tensor solutions. The central region is within $98 \%$ of the maximum fit. It is notable that the deviatoric line along the horizontal axis has solutions that are above $80 \%$ of the maximum fit. The color version of this figure is available only in the electronic edition.

and formed the basis for discriminating the explosion from an earthquake using regional moment tensor analysis.

Finally, we compare the goodness of fit of several other solution types in Table 3. The pure DC and explosion cases, as well as the DC + explosion and tensile-crack + DC are best-fit solutions determined by grid search. A pure explosion fails to fit the data because such a model does not generate $S H$ and Love waves, which are very strong in the long-period records (Fig. 4). The range of solutions on the deviatoric line fits the data substantially worse than any of the solutions that include an isotropic component. This suggests that an isotropic component is indeed needed to provide a good level of fit to the data, although there is uncertainty in terms of what the underlying mechanism may be.

In summary, the evidence for event 10 indicates a substantial and significant departure from a DC mechanism. The NSS distribution and the locations of the best solutions and uncertainty in source-type space, together with the results of the DC + explosion grid search results, indicate that the best mechanism for this event is likely a combination of a DC and 

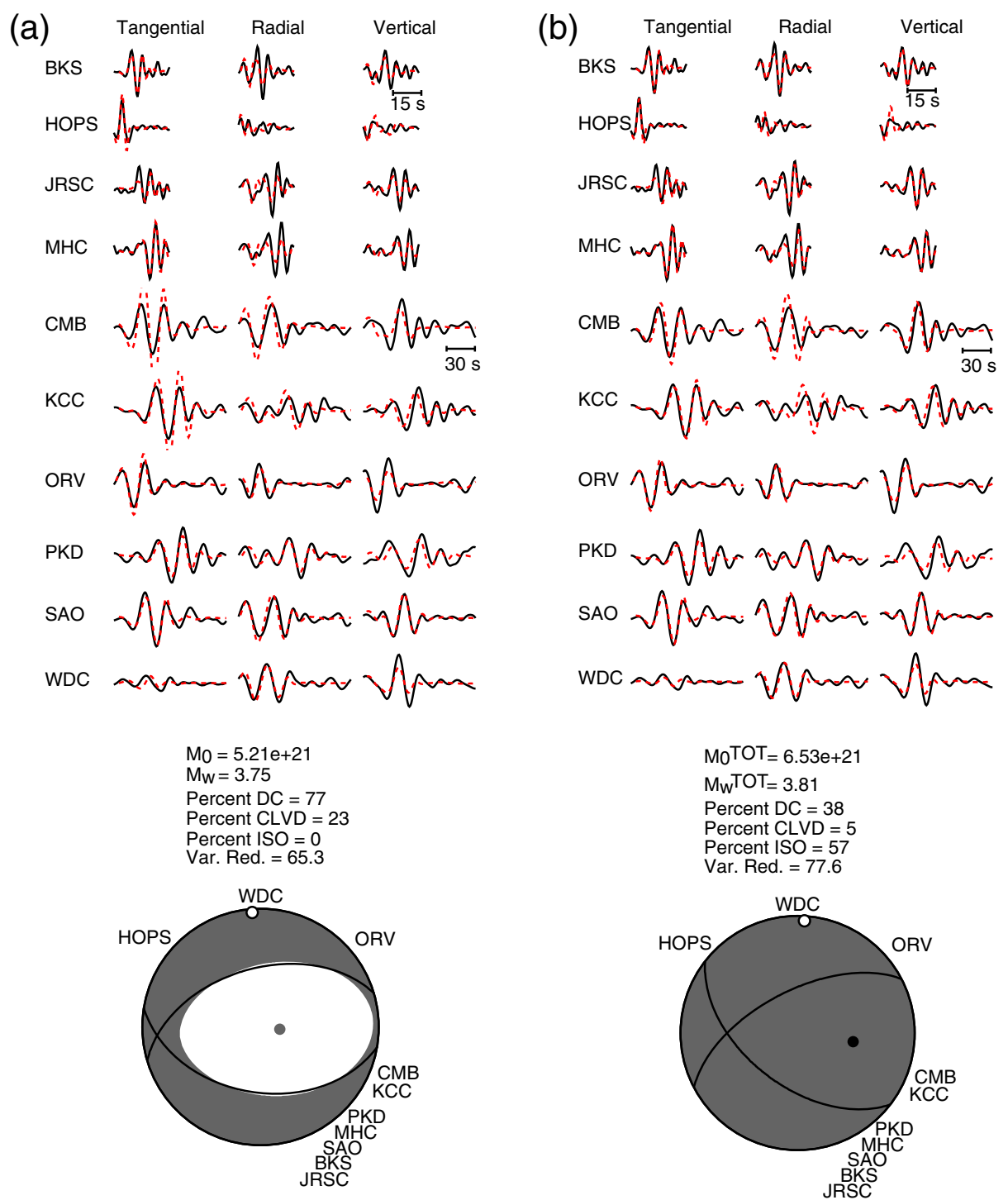

Figure 4. Event 10, 12 October 1996: (a) observed (solid) and synthetic (dashed) waveforms and deviatoric moment tensor solution. (b) Observed (solid) and synthetic (dashed) waveforms and FMT solution. The improvement in fit of the FMT solution is statistically significant at $99 \%$ as determined by the $F$-test. The color version of this figure is available only in the electronic edition.

a spherically symmetric volume-increase source. Examination of first motions, however, indicates a dilatational component at some stations, suggesting that the large volumetric component may not have been the initiating process, but rather followed the DC component. Alternatively, the proportion of volume-increase moment release may have initiated relatively weakly and then developed into the dominant term as the source process evolved. There are several complex source mechanisms that could explain these data including the following: (1) Thermally induced tensile weakening could initiate a shear dislocation that leads to larger tensile failure. The addition of cool injectate into the system could lead to these strong tensile stress conditions (Stark, 2003; Beall et al., 2010). (2) Strain from an initial shear dislocation could cause elevated pore pressures in a sealed region around the dislocation. If pore pressure could exceed the minimum local stress, the pore fluids could subsequently dilate path- ways opened up from faulting damage (Ashby and Sammis, 1990; Lyakhovsky et al., 1997; Johnson and Sammis, 2001; Hamiel et al., 2004; Ben-Zion and Ampuero, 2009).

\section{Examples of Events with a Small Volumetric Component.}

Event 44, with $M_{\mathrm{w}} 4.43$ occurred on 1 March 2011. The deviatoric moment tensor solution is a north-northwest-striking normal DC with a moderate 47\% CLVD component (Fig. 1a). Comparing the VR of the deviatoric solution (79.3\%) with that of the full moment tensor result $(80 \%)$, we find that the best solution indicates a northwest-striking, strike-slip DC (Fig. 1b) with a small (32\%) component of volume increase. However, the fit of the full moment tensor solution is only marginally better, and this is consistent with the $F$-test, which indicates the improvement in fit with the extra degree of freedom rises to a significance level of only 58\%. It should be noted that, for an event with a small volumetric component, the fit will be 


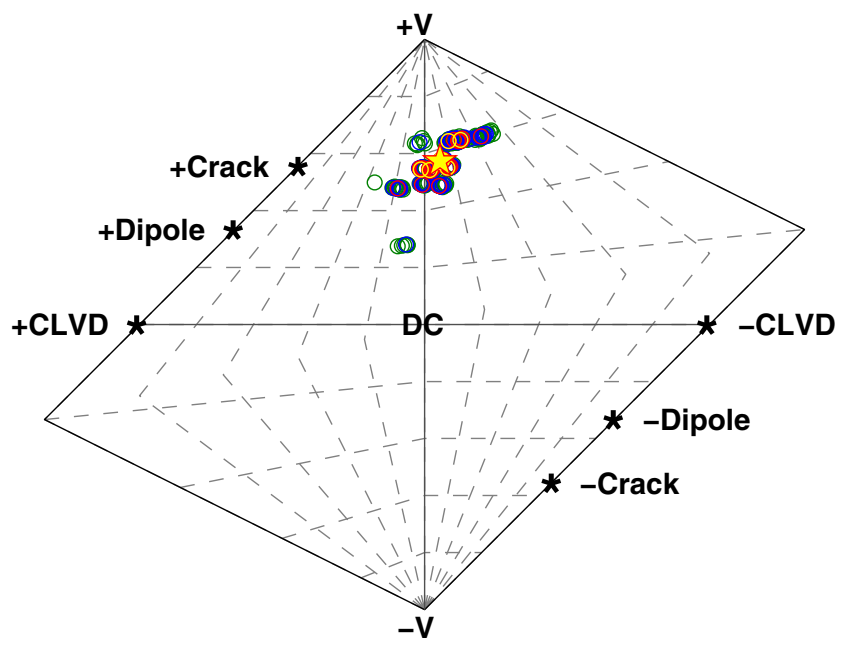

Figure 5. Event 10, 12 October 1996: jackknife tests with subsets of $9,8,7$, and 6 stations (circles) from a total of 10 stations. The star indicates the best 10 -station moment tensor solution. The color version of this figure is available only in the electronic edition.

dominated by the nonvolumetric term. Therefore, the improvement in fit afforded by the volumetric term will be small, resulting in a low level of statistical significance as measured by the $F$-test. An interesting observation for this event, however, is that the full moment tensor inversion is more consistent with the first-motion observations (Fig. 9f).

Following the approach in Ford et al. (2012) and Chiang et al. (2014), in which both long-period waveforms and first motions are combined in an NSS (Ford et al., 2010) analysis, we find a best solution that satisfies both data sets. In this two-step method, the NSS is first evaluated for a large number of uniformly distributed sources. In this case, 200 million moment tensor solutions were considered (Fig. 9b). This

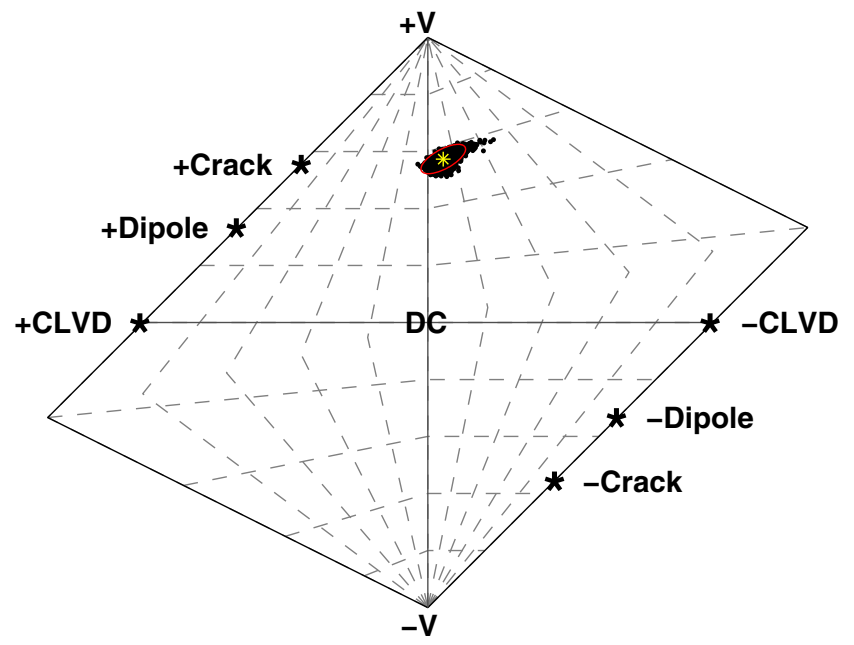

Figure 6. Event 10, 12 October 1996: results of 10,000 bootstrap simulations of residuals from the best moment tensor solution, shown with the asterisk. The $99 \%$ confidence ellipse of the distribution of moment tensor solutions is computed by bootstrapping the residuals. The color version of this figure is available only in the electronic edition.

NSS distribution is different than the two shown in Figures 3c and 8 , for events 41 and 10 , respectively. The solution of event 44 clearly does not have either the signature seen for the DC event 41 discussed previously (Fig. 3c) or for other DC events (Ford et al., 2010; Chiang et al., 2014). It also does not have a peaked or focused fit distribution for a large volume-increase component such as is seen for event 10 in Figure 8. Instead, the NSS fit distribution shows that both deviatoric (large non-DC) and solutions with varying degrees of isotropic radiation satisfy the data through a trade-off. The second step in the methodology is to evaluate the solutions found from the NSS analysis against the first-motion observations. This is accomplished by (a)

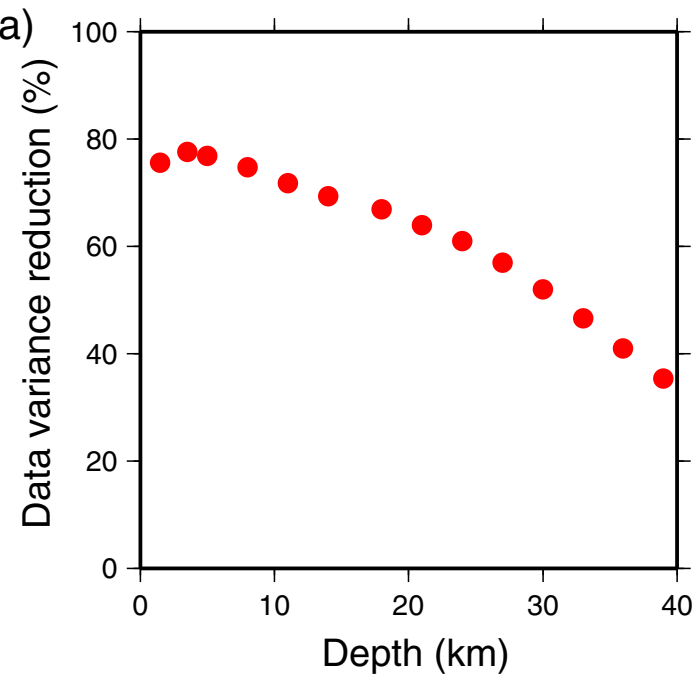

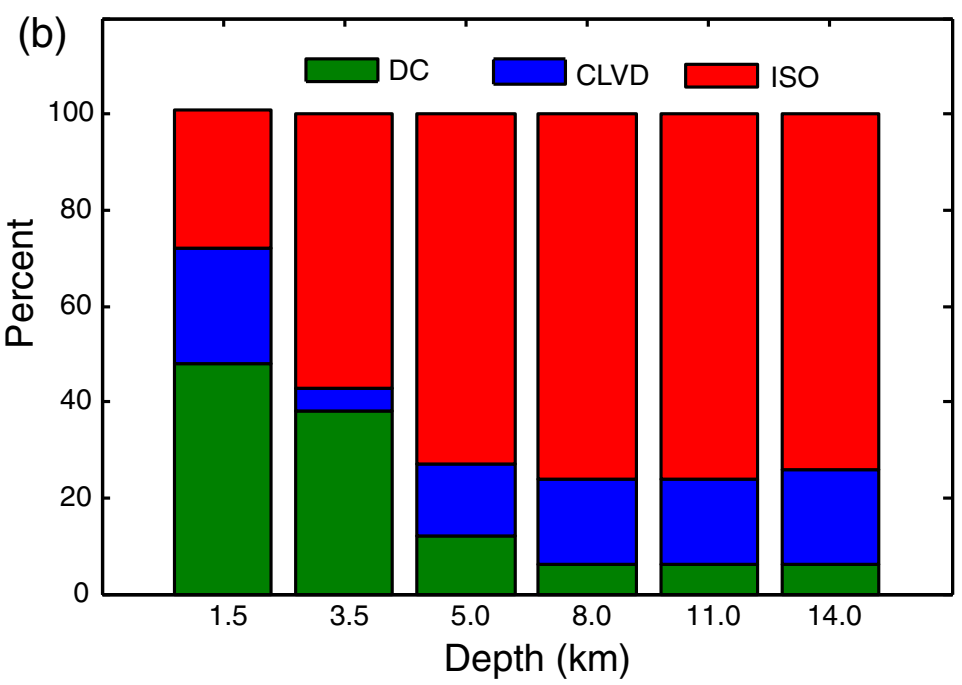

Figure 7. Event 10, 12 October 1996: (a) goodness of fit, expressed as variance reduction of the FMT solutions, as a function of source depth. (b) Relative percentages of DC, CLVD, and ISO (volume-increase) components of the FMT solutions as a function of source depth. The color version of this figure is available only in the electronic edition. 


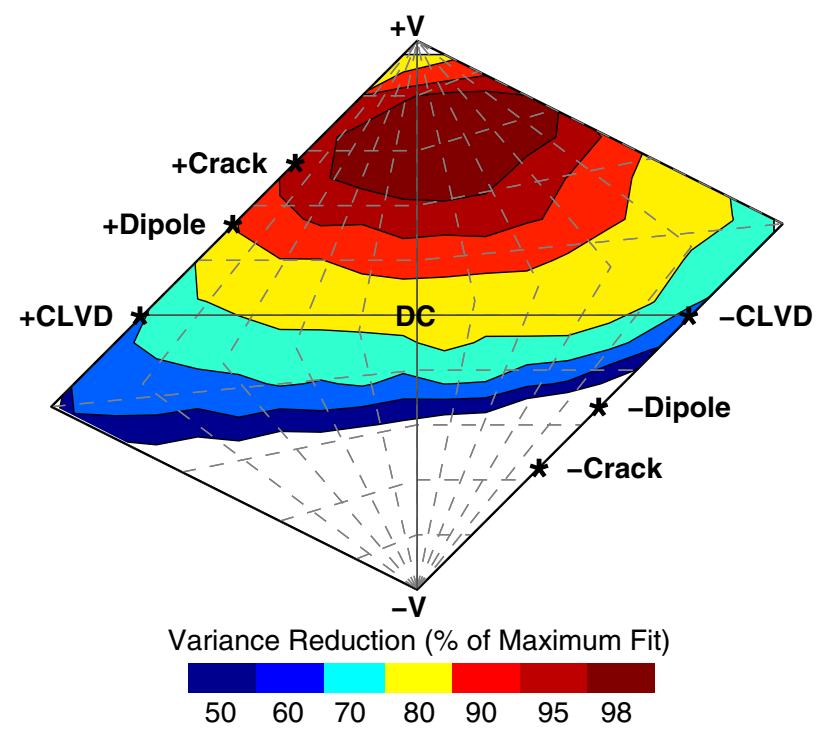

Figure 8. NSS for event 10, 12 October 1996: This plot shows a maximum fit surface in source-type space. The fit is scaled to a maximum fit found from 200 million uniformly distributed moment tensor solutions. The dark shaded region in the upper half is within $98 \%$ of the maximum fit. It is notable that the deviatoric line along the horizontal axis lies in a region where the variance reduction ranges from $70 \%$ to $80 \%$ of the maximum fit. The color version of this figure is available only in the electronic edition.

computing the polarity of the first motions from the NSS solutions and comparing them to the observed first-motion data. The VR is calculated as

$$
\mathrm{VR}=\left(1-\frac{\sum\left(\mathrm{Pol}_{\mathrm{obs}}-\mathrm{Pol}_{\text {synth }}\right)^{2}}{\sum \mathrm{Pol}_{\mathrm{obs}}^{2}}\right) \times 100 .
$$

The combined waveform and first-motion VR is then calculated as

$$
\mathrm{VR}=\left(\mathrm{sVR}_{\mathrm{reg}} \times \mathrm{sVR}_{\mathrm{fm}}\right) \times 100,
$$

in which $\mathrm{sVR}_{\mathrm{reg}}$ and $\mathrm{s} \mathrm{VR}_{\mathrm{fm}}$ are normalized by the maximum waveform and first-motion VR, respectively. This process finds the best waveform-derived solutions that can also explain the first-motion observations.

As can be seen in Figure 9e, there is an inconsistency between the deviatoric solution and the first motions with 42 discrepant observations; the full moment tensor solution, having a low $F$-test significance of $58 \%$, better satisfies the first-motion observations with fewer (29) discrepancies. As discussed above, the solution in Figure $9 \mathrm{~g}$ is obtained by subjecting the NSS analysis to both waveform and first motions. This mechanism provides a reasonably good level of fit to the waveform data, resulting in a $70.2 \%$ VR in waveform fit; and, for the first-motion data, there are only 25 discrepant observations. The DC component is consistent with other DC mechanisms found in the deviatoric analysis in Figure 1a. The small (24\%) isotropic component may be due to tensile failure following weakening caused by the shear dislocation. Tensile stresses are produced by the cooling influence of
Table 3

Model Fits of Event 10, 12 October 1996

\begin{tabular}{llc}
\hline \multicolumn{1}{c}{ Solution Type } & VR & Percent of Maximum VR \\
\hline Full moment tensor & 78 & 100 \\
DC + explosion & 73 & 93.5 \\
Tensile-crack + DC & 72 & 92.3 \\
Deviatoric & 65 & 83.3 \\
Double couple & 64 & 82.1 \\
Explosion & 18 & 23.1 \\
\hline
\end{tabular}

Variance reduction (VR), as defined by equation (3), and percent of maximum VR of different moment tensor decompositions for event 10 .

injectate. Alternatively, the strain associated with the shear dislocation could cause pore pressures to elevate, promoting additional tensile failure if the pore fluids cannot rapidly dissipate. The moment tensor solution $\left(M_{x x}, M_{x y}, M_{x z}, M_{y y}\right.$, $M_{y z}, M_{z z}$ ) for the combined waveform and first-motion inversion is $(-157.82,-243.08,100.58,476.52,36.4,68.36)$ in units of $1 \times 10^{20} \mathrm{dyn} \cdot \mathrm{cm}$.

There are several other events that have the same type of behavior as event 44 . For example, event $37, M_{\mathrm{w}} 3.99$ that occurred on 24 February 2008, has a deviatoric moment tensor solution with a low DC component of $17 \%$ (Fig. 1a). Following the analysis described above, (E) the results for this event are shown in Figure S3. (E) Compressional and dilatational first-motion observations, shown with dark and light plusses, respectively, are displayed with the deviatoric solution in Figure S3e. A high number of stations (48) have discrepant first motions compared with the deviatoric solution. In other words, there is an inconsistency between the deviatoric solution and first-motion observations, whereas the full moment tensor solution, with a higher $F$-test significance $(80 \%)$ than the previous example, better satisfies the first motions with fewer stations (23) that have discrepant observations (E) Fig. S3f). The next step is to subject the NSS analysis to both waveform and first motions, and the best-fit solution is shown in (E) Figure S3g. This mechanism provides a reasonably good level of fit to the waveform data $(69.5 \%$ VR) and results in a minimum of 21 stations that have discrepant first-motion observations. The DC component is consistent with other DC mechanisms found in the deviatoric analysis (Fig. 1a). The moment tensor solution $\left(M_{x x}\right.$, $M_{x y}, M_{x z}, M_{y y}, M_{y z}, M_{z z}$ ) for the combined waveform and first-motion inversion is $(-0.2472,-95.648,-24.37$, $158.45,85.757,124.45)$ in units of $1 \times 10^{20} \mathrm{dyn} \cdot \mathrm{cm}$.

Event $31, M_{\mathrm{w}} 4.71$ that occurred on 12 May 2006, is the largest of the studied events, with a relatively low DC component of $34 \%$. Likewise, with the previous two events, a high number of stations (57) have discrepant first motions compared to the deviatoric solution shown in (E) Figure S4e. Again, there is an inconsistency between the deviatoric solution and the first motions, with 57 discrepant observations, whereas the full moment tensor solution, with a relatively low $F$-test significance $(59.56 \%)$ does not do much better 

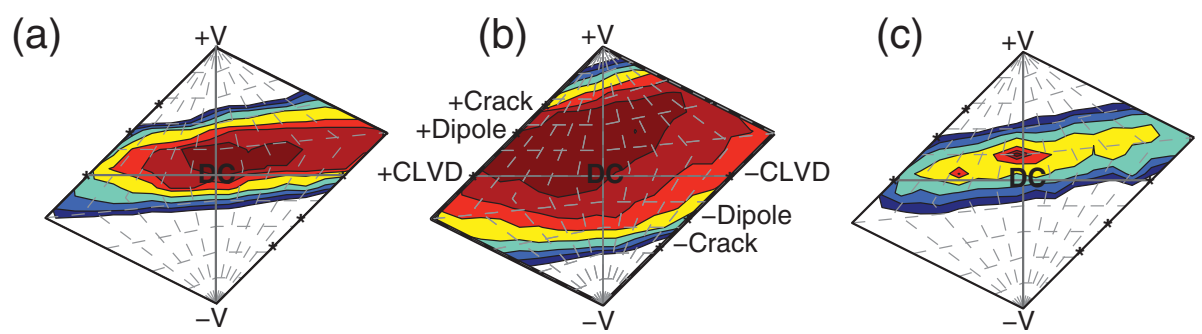

Variance Reduction (\% of Maximum Fit) 50607080909598

(d)
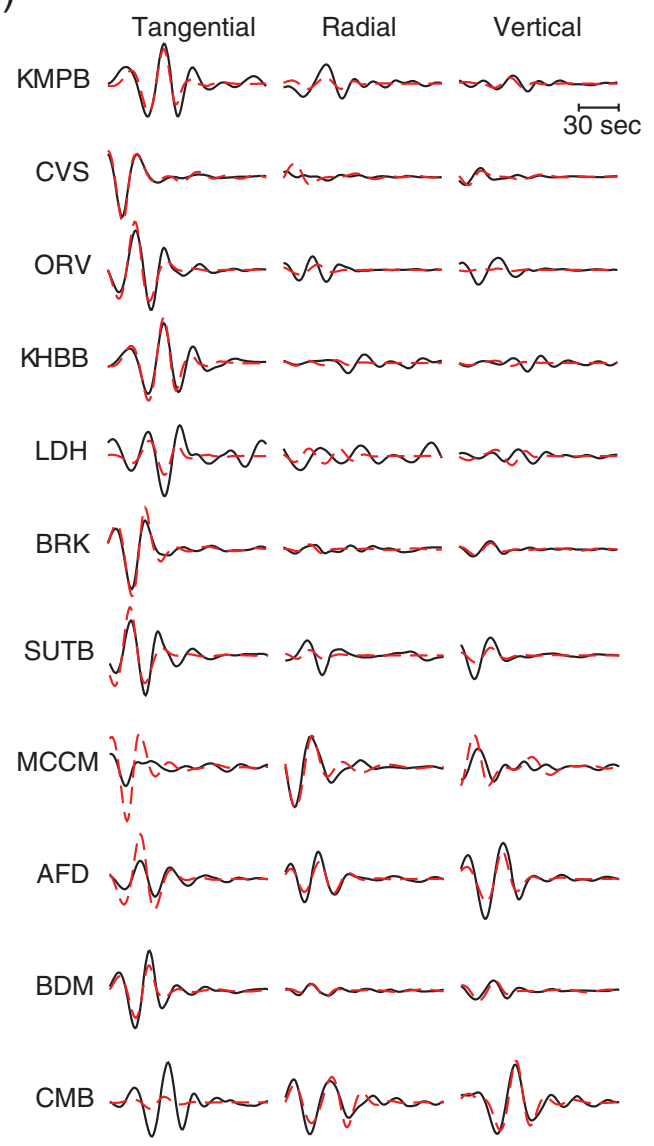

(e)

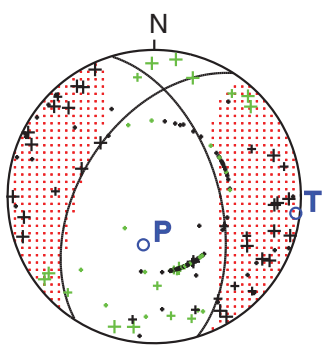

42 discrepant stations

(f)

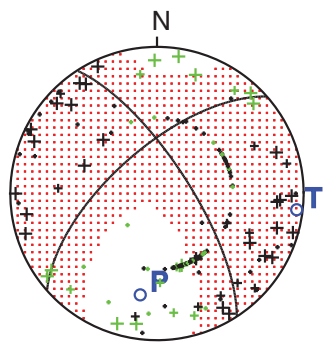

29 discrepant stations

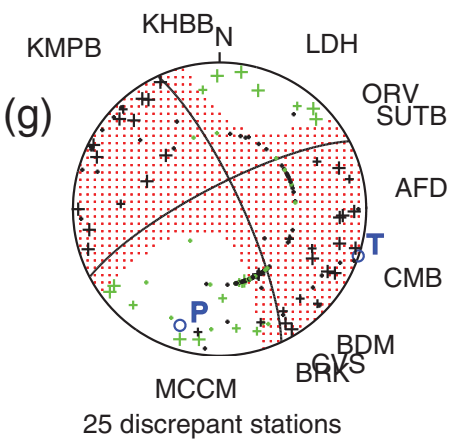

Figure 9. Event 44, 1 March $2011 M_{\mathrm{w}}$ 4.43: (a) NSS for first motions. (b) NSS for FMT waveform analysis. (c) Constrained NSS obtained by testing the output of the waveform NSS against first-motion observations. (d) Observed (solid) and synthetic (dashed) waveforms for the FMT inversion. (e) Deviatoric solution and first motions. Compressional and dilatational first motions are shown with dark and light plusses, respectively. (f) FMT solution and first motions. (g) Constrained FMT (CFTM) solution and first motions. The fit to the first motions in each case is given by the number of stations with first motions inconsistent with the various moment tensor solutions. A high number of stations with discrepant first-motion observations indicates a poor fit. The color version of this figure is available only in the electronic edition.

with 56 discrepant observations (ㅌ) Fig. S4f). As discussed above, by subjecting the NSS analysis to both waveform and first motions, the best-fit solution is shown in (E) Figure S4g. This mechanism provides a relatively poor level of fit to the waveform data, (43.9\% VR) and results in a minimum of 27 stations with discrepant observations. The DC component is consistent with other DC mechanisms found in the deviatoric analysis (Fig. 1a). The moment tensor solution $\left(M_{x x}, M_{x y}\right.$,
$\left.M_{x z}, M_{y y}, M_{y z}, M_{z z}\right)$ for the combined waveform and firstmotion inversion is $(-604.4,123.6,443.4,1235.0,807.6$, 339.9 ) in units of $1 \times 10^{20} \mathrm{dyn} \cdot \mathrm{cm}$.

A final example is event $9, M_{\mathrm{w}} 4.14$ with a $99 \%$ DC component that occurred on 16 January 1995 . The $F$-test evaluating the full moment tensor solution to the deviatoric solution shows an improvement in fit with a significance level of $65 \%$. As seen in (E) Figure S5g, the constrained waveform solution 
Table 4

Summary of First-Motion Fits

\begin{tabular}{cccccccc}
\hline $\begin{array}{c}\text { Date } \\
\text { (yyyy/mm/dd) }\end{array}$ & $\begin{array}{c}\text { Event } \\
\text { Number }\end{array}$ & $M_{\mathrm{w}}$ & $\begin{array}{c}\text { Dev Fit } \\
\text { Disc. FM }\end{array}$ & $\begin{array}{c}\text { FMT Fit } \\
\text { Disc. FM }\end{array}$ & $\begin{array}{c}\text { FMT VR } \\
\text { DC/CLVD/ISO }\end{array}$ & $\begin{array}{c}\text { CFMT Fit } \\
\text { Disc. FM }\end{array}$ & $\begin{array}{c}\text { CFMT VR } \\
\text { DC/CLVD/ISO }\end{array}$ \\
\hline $2011 / 03 / 01$ & 44 & 4.43 & 42 & 29 & $80.042 / 26 / 32$ & 25 & $70.267 / 10 / 24$ \\
$2008 / 02 / 24$ & 37 & 3.99 & 48 & 23 & $78.733 / 19 / 48$ & 21 & $69.543 / 19 / 38$ \\
$2006 / 05 / 12$ & 31 & 4.71 & 57 & 56 & $83.429 / 35 / 36$ & 27 & $43.945 / 34 / 20$ \\
$1995 / 01 / 16$ & 9 & 4.14 & 38 & 40 & $68.927 / 8 / 65$ & 23 & $57.486 / 4 / 10$ \\
\hline
\end{tabular}

Fits to deviatoric (Dev), full moment tensor (FMT), and constrained FMT (CFMT) solutions, as measured by the number of discrepant first-motion (Disc. FM) observations. A high number of discrepant observations indicates a poor fit. Also included are percent components of double couple (DC), compensated linear vector dipole (CLVD), and volume-increase (isotropic, ISO) for FMT and CFMT solutions.

is most consistent with the first-motion data, resulting with the fewest number of discrepant observations (23), compared with the deviatoric (E) Fig. S5e) and full moment tensor (E) Fig. S5f) solutions. As Figure S5e shows, there is an inconsistency between the deviatoric solution and the first motions with 38 discrepant observations. The fit of the first-motion data with the full moment tensor solution is slightly worse, with 40 discrepant observations (E) Fig. S5f). However, the constrained mechanism provides a reasonably good level of fit to the waveform data (57.4\% VR) and results in a minimum of 23 discrepant observations. The DC component is consistent with other DC mechanisms found in the deviatoric analysis (Fig. 1a). The moment tensor solution $\left(M_{x x}, M_{x y}\right.$, $M_{x z}, M_{y y}, M_{y z}, M_{z z}$ ) for the combined waveform and firstmotion inversion is $(49.346,-45.078,-34.259,172.62$, $241.62,-127.21)$ in units of $1 \times 10^{20} \mathrm{dyn} \cdot \mathrm{cm}$.

The results for these four events, listed in Table 4, suggest there may be a relatively small $(10 \%-38 \%)$ volume-increase component in the constrained waveform mechanisms.

\section{Event 10: 12 October $1996 M_{\mathrm{w}} 3.75$, an Anomalous Moment Tensor?}

We applied the constrained full moment tensor (CFMT) method to the 12 October $1996 M_{\mathrm{w}} 3.75$ event (event 10) to gain further insight into the unusually large and statistically significant isotropic component. The first-motion data have both up and down polarities and fit the deviatoric solution better than the full moment tensor solution with fewer discrepant stations (32 compared to 44), as shown in Figure 10d,e. Likewise, the constrained waveform solution, Figure 10f, has a large $65 \%$ DC component, 27\% CLVD component, and $8 \%$ ISO component and is more consistent with the deviatoric solution, but it provides a very poor level of fit to the waveform data (VR $=43.2 \%$ ). Clearly, the high-frequency first-motion data appear to be inconsistent with the long-period moment tensor solution constrained at $3.5 \mathrm{~km}$ depth, the depth of our Green's function closest to the USGS-determined depth of $2.98 \mathrm{~km}$. Even though Figure 7a shows that we have relatively good source depth resolution, and that the best depth of $3.5 \mathrm{~km}$ agrees well with the catalog depth of $2.98 \mathrm{~km}$, we examined in detail the full moment tensor solution at depth $1.5 \mathrm{~km}$ with a $29 \%$ isotropic component, approximately half of that at depth $3.5 \mathrm{~km}$ (Fig. 7b). The first-motion data at depth $1.5 \mathrm{~km}$ fit the deviatoric solution better than the full moment tensor, as shown in Figure 10j and 10k, respectively, with 31 discrepant stations compared to 34 . At the shallower depth, the high-frequency first-motion data are more consistent with the long-period moment tensor solutions and best fit the constrained full waveform solution (47\% DC, 39\% CLVD, and $14 \%$ ISO) with the fewest number (13) of discrepant stations (Fig. 101). For the constrained waveform solution, the waveform fit is also relatively high (68.7\%). The first-motion data are most consistent with the constrained waveform solutions at both depths, each having a relatively high DC component, moderate CLVD, and small ISO component compared with the full moment tensor solutions. However, both solutions produce an inferior fit to the waveform data with lower VRs. From this analysis, it seems that this event requires a volumeincrease component, but its magnitude is complicated by the apparent inconsistency of first-motion and waveform results. The above analysis is predicated on the assumption that the first-motion and long-period waveforms are sensitive to the same source process, which is supported for the previous cases. However, it is also possible that the mechanism of this event could have transitioned from one that was initially shear dominated to one that was subsequently tensile dominated.

\section{Discussion and Conclusions}

Anomalous moment tensor solutions have been reported for past Geysers events (Julian et al. 1993; Ross et al., 1996, 1999). Over the past 22 years, the BSL has published analyst-reviewed seismic moment tensors that now comprise a catalog of 881 events in northern and central California. We found that the distribution of these events, excluding the studied Geysers events, has a mean consistent with a DC mechanism. As was shown in Figure 1b, there are events that deviate from a DC, however, the vast majority of these do not have a level of statistical significance that indicates the isotropic components are resolved. We found that, as a population, the 53 studied events at The Geysers tend to have higher statistical significance of recovered isotropic components and that the mean of the distribution is significantly shifted to positive $K$, as defined in equation (2), indicating volume increase. 
First Motion depth $2.98 \mathrm{~km}$

Green's Function depth $3.5 \mathrm{~km}$

(a)

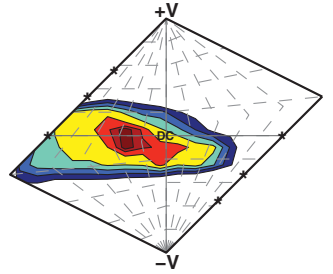

(d)

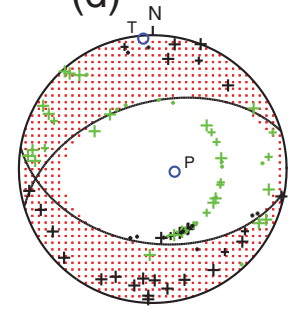

discrepant stations $=32$ VR dev WF $=65.3 \%$ $\mathrm{DC}=77 \%$ CLVD $=23 \%$ (b)

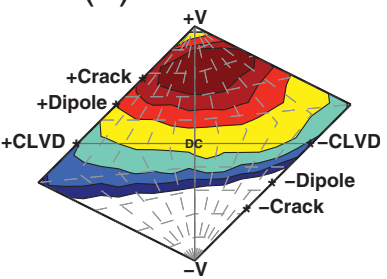

(e)

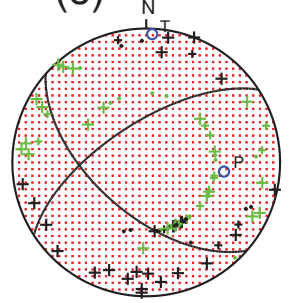

discrepant stations $=44$ VR FMT WF $=77.6 \%$ DC $=38 \%$ CLVD $=5 \%$ ISO $=57 \%$ (c)
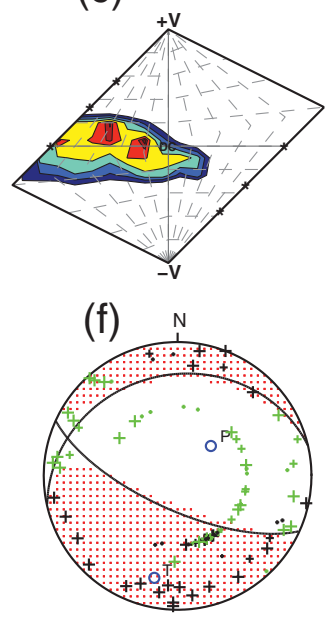

discrepant stations $=16$ VR constrained WF $=43.2 \%$ $\mathrm{DC}=65 \%$ CLVD $=27 \%$ ISO $=8 \%$

First Motion depth $1.5 \mathrm{~km}$ Green's Function depth 1.5 km

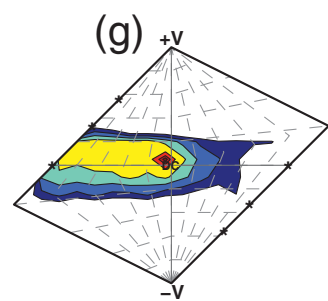

(j)

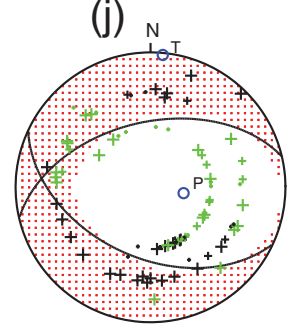

discrepant stations $=31$ VR dev WF $=75.3 \%$ $\mathrm{DC}=61 \%$ CLVD $=39 \%$
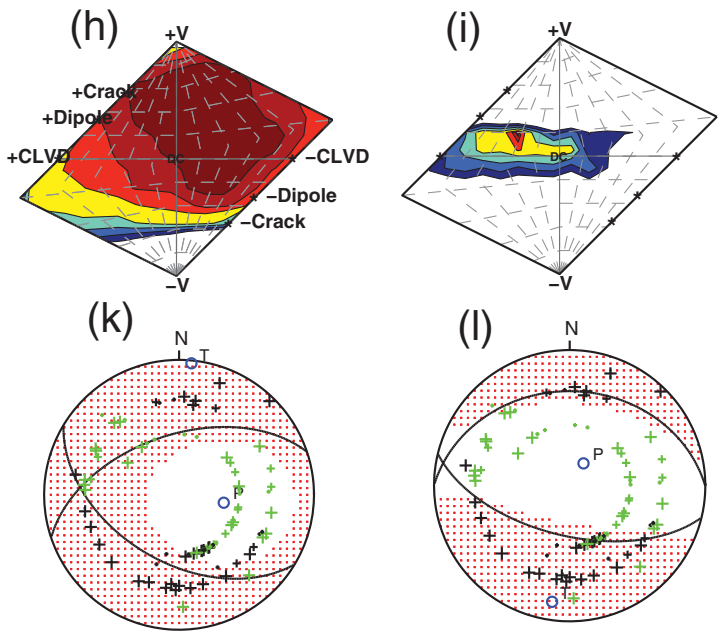

discrepant stations $=34$ VR FMT WF $=75.5 \%$ DC $=48 \%$ CLVD $=24 \%$ ISO $=29 \%$

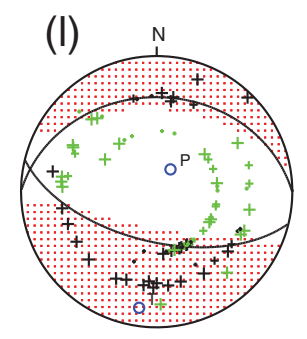

discrepant stations $=13$ VR constrained WF $=68.7 \%$ $\mathrm{DC}=47 \%$ CLVD $=39 \%$ ISO $=14 \%$

Figure 10. Event 10, 12 October $1996 M_{\mathrm{w}}$ 3.57: (a-c) first-motion NSS, FMT waveform inversion NSS, and constrained waveform NSS at depth $3.5 \mathrm{~km}$. (d-e) The deviatoric, FMT, and CFMT solutions at depth $3.5 \mathrm{~km}$ with first motions. Compressional and dilatational first motions are shown with dark and light plusses, respectively. (g-i) Corresponding NSS solutions at depth $1.5 \mathrm{~km}$. (j-l) Corresponding moment tensor solutions and first motions at depth $1.5 \mathrm{~km}$. The color version of this figure is available only in the electronic edition.

It has been shown that care is needed in evaluating the robustness and stability of non-DC and full moment tensor solutions (e.g., Dufumier and Rivera, 1997; Dreger et al., 2000; Vavrycuk, 2001, 2011; Templeton and Dreger, 2006; Minson et al., 2007; Ford et al., 2008, 2009, 2010). We applied a systematic procedure for the evaluation of aleatoric and epistemic solution uncertainty of seismic moment tensor solutions, using bootstrap, jackknife, and NSS approaches to develop solutions that can be used to investigate the underlying mechanical and fluid-mechanical processes that result in the observed seismicity in The Geysers geothermal field.

This staged procedure first uses the $F$-test to evaluate the improvement in fit afforded by the extra degree of freedom of a full moment tensor inversion compared to a deviatoric moment tensor inversion. Based on this criterion, most of the 53 events may be characterized as deviatoric, however, there are 6 events with statistical significance above $80 \%$ and 3 above $90 \%$. In cases in which events are found to have large positive isotropic components, we find from the additional 
sensitivity studies that the results are robust. We also found cases in which small isotropic components are likely, although based on the waveform data alone and the $F$-test, they are not resolved. Through the combination of long-period waveforms and first motions, we are able to obtain stronger constraints on the moment tensor solutions, finding that solutions that best satisfy both data sets are composed of a large strike-slip DC component with a relatively small (10\%-38\%) volume increase. The use of first motions implies commonality of the source process from initiation (first motions) to when the majority of moment release occurs (from the longperiod waveforms), which of course may not always be the case (Scott and Kanamori, 1985).

Event 10 in the southeast Geysers is such an example in which the very large isotropic component predicts compressional first motions at all azimuths and takeoff angles, which is not observed. As shown above, this could be due to source depth, where a shallower source depth reduced the isotropic component and provided a good level of agreement with first-motion polarities but very poor waveform fit. On the other hand, the waveform moment tensor inversion yields a best-fit depth of $3.5 \mathrm{~km}$ that is in agreement with the cata$\log$ depth of $2.98 \mathrm{~km}$. Because of uncertainty in the depth from the moment tensor analysis due to imperfect velocity models and station coverage, we generally restrained our analysis to event depths determined from the NCSS catalog. When event 10 occurred in 1996, the LBNL and USGS seismic networks were smaller and errors in depth may have been greater than those today, especially for events located along the boundaries of the networks. However, it is also possible that as the source process evolved, beginning with a dominant shear mechanism with perhaps a small tensile component, it transitioned into a larger tensile component through a weakening process. The relatively small isotropic components found for other events based on a combined waveform and first-motion analysis indicates that this is a possibility. Tensile stresses in the geothermal field are produced by the cooling influence of injectate and could be a driving mechanism for some of these events.

As we have shown, there are some events that have strong evidence of positive isotropic moment tensor components that suggest a component of tensile failure. These observations are consistent with those of Guilhem et al. (2014) and Johnson (2014a). The extended crack model proposed by Johnson (2014b) accounts for volume increase through the opening of wing cracks at the ends of a shear crack. Not only does this model account for positive isotropic components, it also suggests that two modes of failure, including shear slip and tensile opening, may be sequential. Whether or not this could explain the discrepancy between high-frequency first motions, indicative of a normal mechanism for event 10 , and the long-period moment tensor solution with a $57 \%$ isotropic component would require further analysis. Another relevant point mentioned by Johnson (2014b) is the likelihood that cracks in close proximity may interact. Given the highly fractured subsurface with complex conjugate fault geometries and stress heterogeneity from nearby weakened fault zones, it may be possible that shear slip occurs such that critically stressed fractures, favorably oriented for failure, are reactivated (Majer and McEvilly, 1979; Bufe et al., 1981; McLaughlin, 1981; Eberhart-Phillips and Oppenheimer, 1984; Oppenheimer, 1986; King et al., 1994; Cladouhos et al., 2009; Martinez-Garzon et al., 2013). Two other nearby events, event 27 (27 December $2004 M_{\mathrm{w}} 4.31$, depth $3.71 \mathrm{~km}$ ) and event 46 (29 June 2011 $M_{\mathrm{w}} 3.26$, depth $1.76 \mathrm{~km}$ ) have large isotropic components of $49 \%$ and $52 \%$, respectively. These events occur in the southern part of the reservoir, close to event 10 and have similar mechanisms composed of a north-south tensile stress axis and east-west normal DCs. This may be due to stress heterogeneity from the close proximity of the fractured and weakened east-west-trending Big Sulfur Creek fault zone compared to the surrounding stress regime (Moore and Gunderson, 1995; Cladouhos et al., 2009).

Comparing moment tensor elements from different data sets with different frequency content (e.g., Guilhem et al., 2014) to see how well they agree or disagree may provide insight into the stages of a time-dependent source mechanism, and broadband source analysis would be worthwhile to consider in a future study. The results presented here indicate that seismicity at The Geysers is complex. As a population, the studied events have more significant and larger volumetric components compared to the rest of California; however, based on our analysis, most of the events are likely the result of shear failure due to both tectonic shear stress and tensile stress induced by the injection of water and extraction of steam, but several of the studied earthquakes show evidence of tensile components that could be in response to tensile stress caused by thermal changes due to water injection.

\section{Data and Resources}

Data for this study come from the Berkeley Digital Seismic Network (BDSN; http://dx.doi.org/10.7932/BDSN, last accessed August 2014), operated by the University of California Berkeley Seismological Laboratory, which are archived at the Northern California Earthquake Data Center (NCEDC; http://dx.doi.org/10.7932/NCEDC, last accessed August 2014); Northern California Seismic Network; Lawrence Berkeley National Laboratory; and the Transportable Array. First-motion polarity data were acquired using FPFIT software (Reasenberg and Oppenheimer, 1985) with data from the NCEDC and reviewed using (1) the U.S. Geological Survey Jiggle software, a graphical earthquake analysis tool available for earthquake data processing centers and not intended for general public use, and (2) Seismic Analysis Code (Goldstein et al., 2003). Maps were made using Generic Mapping Tools v.4.5.9 (www.soest.hawaii.edu/gmt, last accessed August 2015; Wessel and Smith, 1998).

\section{Acknowledgments}

The authors thank Associate Editor Stephanie Prejean and three reviewers for their helpful comments and suggestions. We also thank the 
students, staff, and faculty of the University of California Berkeley Seismological Laboratory (BSL) for their contributions to the BSL moment tensor catalog, especially Peggy Hellweg, Taka'aki Taira, Jennifer Taggart, and Tom Weldon; Sean Ford, Aurelie Guilhem, Seung-Hoon Yoo, Mong-Han Huang, Andrea Chiang, and Avinash Nayak for their codes and support; Harold Macbeth and David Oppenheimer, U.S. Geological Survey, and Pete Lombard, BSL, for help with first-motion data, and Craig Hartline, Calpine, for his support in this research. Data for this study come from the Berkeley Digital Seismic Network (BDSN), operated by the UC Berkeley Seismological Laboratory, which is archived at the Northern California Earthquake Data Center (NCEDC). Waveform data, metadata, or data products for this study were accessed through the NCEDC. This work is supported by the Assistant Secretary for Energy Efficiency and Renewable Energy, Office of Geothermal Technologies of the U.S. Department of Energy under Contract Number DE-EE0002756. This is Berkeley Seismological Laboratory Contribution Number 2015-08.

\section{References}

Ashby, M. F., and C. G. Sammis (1990). The damage mechanics of brittle solids in compression, Pure Appl. Geophys. 133, 489-521.

Baig, A., and T. Urbancic (2010). Microseismic moment tensors: A path to understanding frac growth, TLE 29, 320-324.

Barton, D. J., G. R. Foulger, J. R. Henderson, and B. R. Julian (1999). Frequency-magnitude statistics and spatial correlation dimensions of earthquakes at Long Valley Caldera, California, Geophys. J. Int. 138, 563-570.

Beall, J. J., M. C. Wright, A. S. Pingol, and P. Atkinson (2010). Effect of high rate injection on seismicity in The Geysers, Trans. Geoth. Resour. Counc. 34, 1205-1208.

Ben-Zion, Y., and J.-P. Ampuero (2009). Seismic radiation from regions sustaining material damage, Geophys. J. Int. 178, 1351-1356.

Bock, D. E., P. F. Velleman, and R. D. De Veaux (2010). Stats Modeling the World, Third Ed., Pearson Education, Inc., Addison-Wesley, Boston, Massachusetts.

Bowers, D., and J. A. Hudson (1999). Defining the scalar moment of a seismic source with a general moment tensor, Bull. Seismol. Soc. Am. 89, 1390-1394.

Boyle, K., and M. Zoback (2014). The stress state of the Northwest Geysers, California Geothermal Field, and implications for fault-controlled fluid flow, Bull. Seismol. Soc. Am. 104, 2303-2312, doi: 10.1785/0120130284.

Bufe, C. G., S. M. Marks, F. W. Lester, R. S. Ludwin, and M. C. Stickney (1981). Seismicity of the Geysers-Clear Lake Region, in Research in The Geysers-Clear Lake Geothermal Area, Northern California, R. J. McLaughlin and J. M. Donnelly-Nolan (Editors), Geological Survey Professional Paper 1141, U.S. Government Printing Office, Washington, D.C., 129-137.

Chiang, A., D. S. Dreger, S. R. Ford, and W. R. Walter (2014). Source characterization of underground explosions from combined regional moment tensor and first-motion analysis, Bull. Seismol. Soc. Am. 104, 1587-1600, doi: 10.1785/0120130228.

Cladouhos, T., S. Petty, B. Larson, J. Iovenitti, B. Livesay, and R. Baria (2009). Toward more efficient heat mining: A planned enhanced geothermal system demonstration project, Trans. Geoth. Resour. Counc. 33, 165-170.

Cuenot, N., J. Charlety, L. Dorbath, and H. Haessler (2006). Faulting mechanisms and stress regime at the European HDR site of Soultz-sous-Forets, France, Geothermics 35, 561-575.

Deichmann, N., and D. Giardini (2009). Earthquakes induced by the stimulation of and enhanced geothermal system below Basel (Switzerland), Seismol. Res. Lett. 80, 784-798.

Dreger, D. S., H. Tkalcic, and M. Johnston (2000). Dilational processes accompanying earthquakes in the Long Valley Caldera, Science 288, 122-125.

Dufumier, H., and L. Rivera (1997). On the resolution of the isotropic component in moment tensor inversion, Geophys. J. Int. 131, 595-606.

Dziewonski, A. M., and J. H. Woodhouse (1983). An experiment in systematic study of Global Seismicity-Centroid Moment Tensor solutions for 201 moderate and large earthquakes of 1981, J. Geophys. Res. 88, 3247-3271.

Eberhart-Phillips, D., and D. H. Oppenheimer (1984). Induced seismicity in The Geysers geothermal area, California, J. Geophys. Res. 89, 1191-1207.

Enedy, S., K. Enedy, and J. Maney (1991). Reservoir response to injection in the southeast Geysers, Proc. Sixteenth Workshop on Geothermal Reservoir Engineering, Stanford University, Stanford, California, SGP-TR-134.

Fichtner, A., and H. Tkalcic (2010). Insights into the kinematics of a volcanic caldera drop: Probabilistic finite-source inversion of the 1996 Bardarbunga, Iceland, earthquake, Earth Planet. Sci. Lett 297, 607-615.

Ford, S. R., D. Dreger, and W. Walter (2008). Source characterization of the August 6, 2007 Crandall Canyon mine seismic event in central Utah, Seismol. Res. Lett. 79, 637-644.

Ford, S. R., D. S. Dreger, and W. R. Walter (2009). Identifying isotropic events using a regional moment tensor inversion, J. Geophys. Res. 114, no. B01306, doi: 10.1029/2008JB005743.

Ford, S. R., D. S. Dreger, and W. R. Walter (2010). Network sensitivity solutions for regional moment tensor inversions, Bull. Seismol. Soc. Am. 100, 1962-1970.

Ford, S. R., W. R. Walter, and D. S. Dreger (2012). Event discrimination using regional moment tensors with teleseismic- $P$ constraints, Bull. Seismol. Soc. Am. 102, 867-872.

Godano, M., T. Bardainne, M. Regnier, and A. Deschamps (2011). Momenttensor determination by nonlinear inversion of amplitudes, Bull. Seismol. Soc. Am. 101, 366-378.

Goldstein, P., D. Dodge, M. Firpo, and L. Minner (2003). SAC2000: Signal processing and analysis tools for seismologists and engineers, in International Handbook of Earthquake and Engineering Seismology, W. H. K. Lee, H. Kanamori, P. C. Jennings, and C. Kisslinger (Editors), Vol. 81B, Academic Press, London, United Kingdom, 1613-1614.

Greensfelder, R. W. (1993). New evidence of the causative relationship between well injection and microseismicity in The Geysers geothermal field, Trans. Geoth. Resour. Counc. 17, 243-247.

Guilhem, A., L. Hutchings, D. S. Dreger, and L. R. Johnson (2014). Moment tensor inversions of $\mathrm{M} \sim 3$ earthquakes in the Geysers geothermal fields, California, J. Geophys. Res. 119, 2121-2137.

Hamiel, Y., V. Lyakhovsky, and A. Agnon (2004). Coupled evolution of damage and porosity in poroelastic media: Theory and applications to deformation of porous rocks, Geophys. J. Int. 156, 701-713.

Hamilton, R. M., and L. J. P. Muffler (1972). Microearthquakes at The Geysers geothermal area, California, J. Geophys. Res. 77, 2081-2086.

Horalek, J., Z. Jechumtalova, L. Dorbath, and J. Sileny (2010). Source mechanisms of micro-earthquakes induced in a fluid injection experiment at the HDR site Soultz-sous-Forets (Alsace) in 2003 and their temporal and spatial variations, Geophys. J. Int. 181, 1547-1565.

Hudson, J. A., R. G. Pearce, and R. M. Rogers (1989). Source type plot for inversion of the moment tensor, J. Geophys. Res. 94, 765-774.

Johnson, L. R. (2014a). Source mechanisms of induced earthquakes at The Geysers geothermal reservoir, Pure Appl. Geophys. 171, doi: 10.1007/ s00024-014-0795-x.

Johnson, L. R. (2014b). A source model for induced earthquakes at The Geysers geothermal reservoir, Pure Appl. Geophys. 171, doi: 10.1007/s00024-014-0798-7.

Johnson, L. R., and C. G. Sammis (2001). Effects of rock damage on seismic waves generated by explosions, Pure Appl. Geophys. 158, 1869-1908.

Julian, B. R., A. D. Miller, and G. R. Foulger (1993). Non-shear focal mechanisms of earthquakes at The Geysers, California, and Hengill, Iceland, geothermal areas, Trans. Geoth. Resour. Counc. 17, 123-128.

King, G. C. P., R. S. Stein, and J. Lin (1994). Static stress changes and the triggering of earthquakes, Bull. Seismol. Soc. Am. 84, 935-953.

Kirkpatrick, A., J. E. Peterson, and E. L. Majer (1996). Source mechanisms of microearthquakes at the southeast Geysers geothermal field, California, Proc. Twenty-First Workshop on Geothermal Reservoir Engineering, Stanford University, Stanford, California, SGP-TR-151, 359-366. 
Kirkpatrick, A., J. E. Peterson, E. L. Majer, and R. Nadeau (1999) Characteristics of microseismicity in the DV11 injection area, southeast Geysers, California, Proc. Twenty-Fourth Workshop on Geothermal Reservoir Engineering, Stanford University, SGP-TR-162.

Knopoff, L., and M. J. Randall (1970). The compensated linear vector dipole: A possible mechanism for deep earthquakes, J. Geophys. Res. 75, 4957-4963.

Lange, A. L., and W. H. Westphal (1969). Microearthquakes near the Geysers, Sonoma County, California, J. Geophys. Res. 74, 4377-4378.

Lyakhovsky, V., Y. Ben-Zion, and A. Agnon (1997). Distributed damage, faulting, and friction, J. Geophys. Res. 102, 27,635-27,649.

Majer, E. L., and T. V. McEvilly (1979). Seismological investigations at the Geysers geothermal field, Geophysics 44, 246-269.

Majer, E. L., and J. E. Peterson (2005). Application of microearthquake monitoring for evaluating and managing the effects of fluid injection at naturally fractured EGS sites, Trans. Geoth. Resour. Counc. 29, 103-107.

Majer, E. L., R. Baria, M. Stark, S. Oates, J. Bommer, and H. Asanuma (2007). Induced seismicity associated with enhanced geothermal systems, Geothermics 36, 185-222.

Marks, S. M., R. S. Ludwin, K. B. Louie, and C. G. Bufe (1978). Seismic Monitoring at The Geysers Geothermal Field, California, U.S. Geol. Surv. Open-File Rept. 78-798.

McLaughlin, R. J. (1981). Tectonic setting of pre-Tertiary rocks and its relation to geothermal resources in The Geysers-Clear Lake area, in Research in The Geysers-Clear Lake Geothermal Area, Northern California, R. J. McLaughlin and J. M. Donnelly-Nolan (Editors), U.S. Geol. Surv. Profess. Pap. 1141, 3-23.

Martinez-Garzon, P., M. Bonhoff, G. Kwiatek, and G. Dresen (2013). Stress tensor changes related to fluid injection at The Geysers geothermal field, California, Geophys. Res. Lett. 40, 2596-2601, doi: 10.1002/grl.50438.

Minson, S., and D. Dreger (2008). Stable inversions for complete moment tensors, Geophys. J. Int. 174, 585-592.

Minson, S., D. Dreger, R. Burgmann, H. Kanamori, and K. Larsen (2007) Seismically and geodetically determined non-double-couple source mechanisms from the 2000 Miyakejima volcanic earthquake swarm, J. Geophys. Res. 112, no. B10308, doi: 10.1029/2006JB004847.

Moore, J. N., and R. P. Gunderson (1995). Fluid-inclusion and oxygenisotopic systematics of an evolving magmatic-hydrothermal system, Geochim. Cosmochim. Acta 59, 3887-3907.

Nayak, A., and D. S. Dreger (2014). Moment tensor inversion of seismic events associated with the Sinkhole at Napoleonville Salt Dome, Louisiana, Bull. Seismol. Soc. Am. 104, 1763-1776, doi: 10.1785/0120130260.

Nettles, M., and G. Ekstrom (1998). Faulting mechanism of anomalous earthquakes near Bardarbunga volcano, Iceland, J. Geophys. Res. 103, 17,973-17,983.

O'Connell, D. R. H., and L. R. Johnson (1988). Second-order moment tensors of microearthquakes at The Geysers geothermal field, California, Bull. Seismol. Soc. Am. 78, 1674-1692.

Oppenheimer, D. H. (1986). Extensional tectonics at The Geysers geothermal area, California, J. Geophys. Res. 91, 11,463-11,476.

Pasyanos, M. E., D. S. Dreger, and B. Romanowicz (1996). Toward real-time estimation of regional moment tensors, Bull. Seismol. Soc. Am. 86, 1255-1269.

Reasenberg, P. A., and D. Oppenheimer (1985). FPFIT, FPPLOT, and FPPAGE: Fortran computer programs for calculating and displaying earthquake fault-plane solutions, U.S. Geol. Surv. Open-File Rept. 85-739.
Ross, A., G. R. Foulger, and B. R. Julian (1996). Non-double-couple earthquake mechanisms at The Geysers geothermal area, California, Geophys. Res. Lett. 23, 877-880.

Ross, A., G. R. Foulger, and B. R. Julian (1999). Source processes of industrially-induced earthquakes at The Geysers geothermal area, California, Geophysics 64, 1877-1889.

Scott, D. S., and H. Kanamori (1985). On the consistency of moment tensor source mechanisms with first-motion data, Phys. Earth Planet. In. 37, $97-107$.

Shimizu, H., S. Ueki, and J. Koyama (1987). A tensile-shear crack model for the mechanism of volcanic earthquakes, Tectonophysics 144, 287-300.

Smith, B., J. Beall, and M. Stark (2000). Induced seismicity in the SE Geysers field, California, USA, Proceedings World Geothermal Congress, Kyushu-Tohoku, Japan, 28 May-10 June 2000.

Stark, M. (2003). Seismic evidence for a long-lived enhanced geothermal system (EGS) in the northern Geysers reservoir, Trans. Geoth. Resour. Counc. 27, 727-731.

Stark, M. A. (1990). Imaging injected water in The Geysers reservoir using microearthquake data, Trans. Geoth. Resour. Counc. 14, 1697-1704.

Templeton, D. C., and D. S. Dreger (2006). Non-double-couple earthquakes in the Long Valley volcanic region, Bull. Seismol. Soc. Am. 96, 69-79.

Tkalcic, H., D. S. Dreger, G. R. Foulger, and B. R. Julian (2009). The puzzle of the 1996 Bardarbunga, Iceland, earthquake: No volumetric component in the source mechanism, Bull. Seismol. Soc. Am. 99, 3077-3085, doi: $10.1785 / 0120080361$.

Vavrycuk, V. (2001). Inversion for parameters of tensile earthquakes, J. Geophys. Res. 106, 16,339-16,355.

Vavrycuk, V. (2011). Tensile earthquakes: Theory, modeling, and inversion, J. Geophys. Res. 116, no. B12, doi 10.1029/2011JB008770.

Walter, F., J. F. Clinton, N. Deichmann, D. S. Dreger, S. E. Minson, and M. Funk (2009). Moment tensor inversions of icequakes on Gornergletscher, Switzerland, Bull. Seismol. Soc. Am. 99, 852-870.

Walter, F., D. S. Dreger, J. F. Clinton, N. Deichmann, and M. Funk (2010). Evidence for near-horizontal tensile faulting at the base of Gornergletscher, a Swiss alpine glacier, Bull. Seismol. Soc. Am. 100, 458-472.

Wang, C. Y., and R. B. Herrmann (1980). A numerical study of $P-, S V-$, and SH-wave generation in a plane layered medium, Bull. Seismol. Soc. Am. 70, 1015-1036.

Wessel, P., and W. H. F. Smith (1998). New, improved version of Generic Mapping Tools released, Eos Trans. AGU 79, 579.

Berkeley Seismological Laboratory

215 McCone Hall Number 4760

Berkeley, California 94720-4760

sierra@seismo.berkeley.edu

(O.S.B., D.S.D., V.H.L.)

Array Information Technology

2020 Cedar Street

Berkeley, California 94709

(R.G.)

Manuscript received 27 August 2015;

Published Online 10 November 2015 